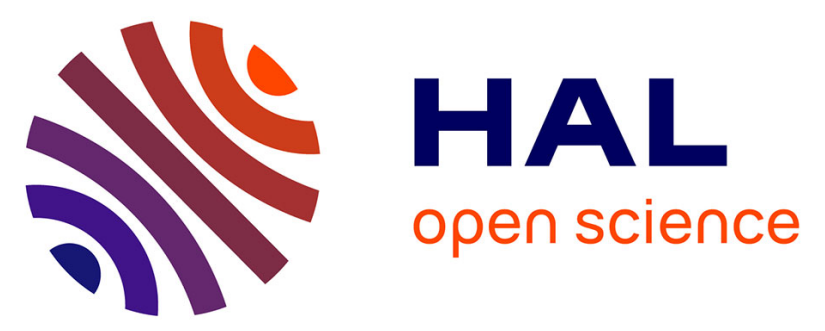

\title{
Secondary students' thinking about familiar phenomena: learners' explanations from a curriculum context where 'particles' is a key idea for organising teaching and learning
} Alejandra García Franco, Keith Stephen Taber

\section{To cite this version:}

Alejandra García Franco, Keith Stephen Taber. Secondary students' thinking about familiar phenomena: learners' explanations from a curriculum context where 'particles' is a key idea for organising teaching and learning. International Journal of Science Education, 2009, 31 (14), pp.1917-1952. 10.1080/09500690802307730 . hal-00516242

\section{HAL Id: hal-00516242 \\ https://hal.science/hal-00516242}

Submitted on 9 Sep 2010

HAL is a multi-disciplinary open access archive for the deposit and dissemination of scientific research documents, whether they are published or not. The documents may come from teaching and research institutions in France or abroad, or from public or private research centers.
L'archive ouverte pluridisciplinaire HAL, est destinée au dépôt et à la diffusion de documents scientifiques de niveau recherche, publiés ou non, émanant des établissements d'enseignement et de recherche français ou étrangers, des laboratoires publics ou privés. 


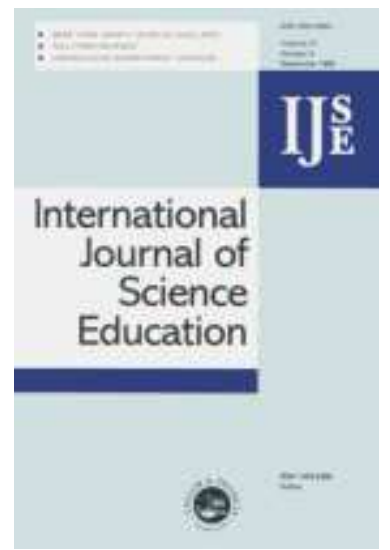

Secondary students' thinking about familiar phenomena: learners' explanations from a curriculum context where 'particles' is a key idea for organising teaching and learning

\begin{tabular}{|r|l|}
\hline Journal: & International Journal of Science Education \\
\hline Manuscript ID: & TSED-2007-0349.R2 \\
\hline Manuscript Type: & Research Paper \\
\hline Keywords: & $\begin{array}{l}\text { alternative conception, chemistry education, conceptual } \\
\text { development, curriculum, explanation }\end{array}$ \\
\hline Keywords (user): & particles \\
\hline
\end{tabular}

\section{S) ScholaroNE \\ Manuscript Central}




\title{
Secondary students' thinking about familiar phenomena: learners' explanations from a curriculum context where 'particles' is a key idea for organising teaching and learning.
}

\begin{abstract}
:
Particle models of matter are widely recognised as being of fundamental importance in many branches of modern science, and particle ideas are commonly introduced and developed in the secondary school curriculum. However, research undertaken in a range of national contexts has identified significant learning difficulties in this topic, and suggests that notions of particles that match scientific models are generally only attained over periods of some years. A National Curriculum in Science was imposed in England over the period 1989-1993, and was later supplemented by increasingly prescriptive guidance to teachers. This culminated in a framework for teaching lower secondary science, which identified 'particles' as one of five key ideas for organising teaching and learning. In this curriculum context, a basic particle model is introduced at the start of secondary education, and consolidated by being revisited in various contexts over three years. The present paper reports an interview-about-events based study that explored the way English secondary students explained phenomena commonly met in school science. It was found that most students used the notion of particles in their responses, although most of their particle-based explanations reflected alternative conceptions that have been reported in previous research. It is concluded that a curriculum strategy of early introduction and regular application during the early secondary years is not sufficient to support the desired level of progression in thinking with particle concepts, and more sophisticated pedagogy is needed.
\end{abstract}




\title{
Secondary students' thinking about familiar phenomena: student explanations in a curriculum context where 'particles' is a key idea for organising teaching and learning.
}

\author{
Introduction \\ This paper considers findings from an interview study that explored secondary level \\ students' explanations of basic phenomena commonly met in school chemistry. The \\ study was carried out in a curriculum context where the notion of 'particles' is \\ explicitly considered one of the 'key ideas' around which science teaching should be \\ structured. Previous research (discussed below) has highlighted the difficulties that \\ many students have in acquiring an understanding of the models used by scientists to \\ describe matter at submicroscopic level. The importance of this topic in science is \\ widely acknowledged, as are some of the reasons why it provides a challenge to \\ school age learners (Lijnse, Licht, de Vos, \& Waarlo, 1990; Author1, 2001; Harrison \\ \& Treagust, 2002).
}

In recent years the UK government has funded an extensive initiative to develop pedagogic strategies and support teaching of the English national science curriculum. This guidance, supplemented by associated professional development support, has been organised around five 'key ideas', one of which is 'particles'. This new curriculum context provided the background for the study reported here, which explored the way students explained basic phenomena that school science would model in terms of the interactions and properties of particles such as molecules and ions. In particular, we have analysed student explanations offered in interviews to investigate whether the explicit status of 'particles' as a key idea, and the investment in teacher support designed to 'strengthen teaching and learning of particles' (KS3NS, 2003a, 2003b) has facilitated teaching that has overcome the well-reported learning difficulties in this topic.

In this paper we briefly describe the centrality of the particle concept in the current English secondary science curriculum, as a context for reporting the results of an analysis of our interviews in terms of the extent to which students drew upon 'target 


\begin{abstract}
knowledge' when explaining basic phenomena such as dissolving. Our informants commonly used a notion of particles in their explanations, although generally not in $\underline{\text { ways consistent with the teaching models. The study is not based upon a }}$ representative sample of English secondary pupils, but we note that these findings are consistent with the outcomes of official National Testing of all pupils at age 14. As
\end{abstract} the English context is one where considerable official guidance and support has been provided to 'strengthen' teaching and learning about particles (KS3NS, 2003a, $\underline{2003 \mathrm{~b}}$ ), we might imagine this offers something of a 'best-case' scenario, and so we Deleted: DfES consider our findings are potentially significant for all educational systems where secondary level students are taught particle models of matter.

\title{
The centrality of particle models in science
}

Particle ideas are central to modern science. Indeed Richard Feynman suggested that

if only one idea from science was to survive some future cataclysm, then the notion

Deleted: idea that everything is made of tiny particles, with inherent motion, that attracted or repelled each other depending upon separation, would be his candidate for the most useful starting point for rebuilding (reported in Feynman, Leighton \& Sands, 1963: 12). As Feynman pointed out, a great deal can be deduced and understood from that hypothesis. Increasingly detailed refinements of this basic idea are central to many branches of modern science.

The centrality of particle models in science has led to particle ideas being given high prominence in the science curriculum in many countries (e.g. MoE, 1993; NAS, 1996; DfEE/QCA, 1999). Within Chemistry, the concept is fundamental to any kind of advanced study (e.g. Ault, Novak and Gowin, 1984).

\section{Students' difficulties in learning about particles}

It is well established that students find these ideas difficult to learn (e.g. Renström, Andersson \& Marton, 1990; Nussbaum \& Novick, 1982; Ault, Novak \& Gowin, 1984; Ben-Zvi, Eylon \& Silberstein, 1986; Briggs \& Holding, 1986; Wightman, Green \& Scott, 1986; Griffiths \& Preston, 1992; Harrison \& Treagust, 2002; Author1, 2003). Hesse \& Anderson (1992: 277) reported from their study of high schools students who had completed a unit of study on chemical change that, despite 
the emphasis on particle ideas in their course, most of the students failed "to invoke atoms and molecules as explanatory constructs".

For many secondary age learners, the particle models of matter presented in the curriculum offer a considerable learning demand, i.e. the extent to which target knowledge differs from a student's current understanding (Leach and Scott, 2002). These 'particles' - molecules, ions, atoms etc. - have properties quite unlike the particles (i.e. grains, specks) of students' everyday experience. Indeed the use of a familiar term may ultimately be unhelpful (cf. Watts \& Gilbert, 1983; Schmidt, 1991), and it has been suggested that an alternative such as 'quanticles' might be advisable (Author1, 2004).

Some studies show quite fundamental misunderstandings of the scientific models represented in the science curriculum (Author1, 2001). For example, when first learning about particles, it is not unusual for learners to conceptualise particles embedded within materials (rather than materials composed only of the particles), or to assume that air flows between the particles (Nussbaum \& Novick, 1982; Ault, Novak \& Gowin, 1984; Renström, Andersson \& Marton, 1990; Griffiths and Preston, 1992; Wightman, Green \& Scott, 1986; 195).

Learners may also fail to appreciate how the fundamental particles of a substance can be identical (Griffiths \& Preston, 1992), and unchanged during a change of state (Ben-Zvi, Eylon \& Silberstein, 1986; Ault, Novak \& Gowin, 1984; Wightman et al., 1986: 276; Griffiths \& Preston 1992). The notion of particles having inherent Deleted: , p. unceasing motion also proves difficult for learners (Nussbaum \& Novick, 1982; Wightman et al, 1986).

Where scientists explain the properties of materials in terms of the conjectured (different) properties of the component particles, students will often simply assign the macroscopic property to the particle, and then use this as an explanation (Renström, Andersson \& Marton, 1990; Griffiths \& Preston, 1992; Briggs \& Holding, 1986), e.g. solids are hard because they are made up from hard particles. Ben-Zvi, Eylon and Silberstein (1986) found that nearly half (c.46\%) of a sample of 300 Israeli high school students (aged about 15 years) ascribed inappropriate properties of a material to its individual atoms: properties such as electrical conduction, malleability, colour, 
odour and reactivity. It is also common for students' explanations in terms of particles to be teleological or anthropomorphic, e.g. the particles _want' to move away from each other (Driver, 1983; Wightman et al, 1986; Griffiths \& Preston, 1992; Author1 $\&$ Colleague, 1996).

\section{Progression in understanding particle models}

Just as lower secondary level students experience problems making sense of the basic particle theory introduced in school science, more advanced high school students commonly have difficulty acquiring the more complex particle models involving atoms, molecules, ions, electrons, etc. that are presented at upper secondary (high school) level (Author1, 2001) - something that should not be surprising as the basic model provides the foundations for the more advanced models.

Similarly, the yet more nuanced and sophisticated models introduced in college level studies, which build in turn on the learning prescribed (but not always achieved) in upper secondary school, lead to further difficulties for the group of students interested and successful enough to opt for further science studies (Harrison \& Treagust, 2000; Author1, 2004; Colleague \& Author1, 2007).

\section{Developing understanding of particle ideas}

Renström, Andersson and Marton interviewed 20 Swedish pupils in grades 7-9 (i.e. 13 - 16 years of age) about their "understanding of one of the most central questions in chemistry: the nature of matter" (1990, p.555). In their interview study Renström and coworkers used nine common materials as foci for discussion: salt, iron, aluminum, wood, water, oil, air, oxygen and carbon dioxide. They had a prepared script of questions, but also followed up the range of responses on an individual basis. The analysis of interview protocols followed what they called "a nonalgorithmic, interpretative 'discovery procedure'..." (Renström et al., 1990, p.557) leading to a

description of possible ways of thinking about matter,

Deleted: Learners' ideas about matter were explored by

Deleted:

Deleted: who

Six distinct 'conceptions of matter' were identified, although "the same student can very well adopt different conceptions as a background for reasoning about different problems and different substances" (p.558). The six conceptions were:

(a) a homogeneous substance - the substance is not delimited from other substances and it lacks substance attributes. 
(b) the substance is delimited from other substances and it exists in more than one form (which creates the potential for thinking of phase transition).

(c) substance units with small particles that may be different from the substance in which they are embedded (which creates the potential for thinking of atoms, which are components of the substance but do not have its macroproperties).

(d) aggregates of particles - the substance consists of infinitely divisible particles, which might not consist of the substance.

(e) particle units - the substance consists of particles that are not divisible into other particles and that have certain attributes (such as form and structure) that may explain macroproperties of the substance.

(f) systems of particles - the substance consists of systems of particles. Different macroproperties of the substance can be accounted for in terms of particles and particle systems.

Renström et al., 1990: 558, 560, 565-566.

Renström et al considered these six conceptions to form a hierarchy (p.558) in terms

of increasing explanatory power and more detailed understanding, so that at the

Deleted: (pp.565-566) higher levels of the scheme the increasing sophistication of the conceptions begins to approach the notion of matter presented in school science as target knowledge.

Renström et al reported that even those learners operating at the most inclusive level of the hierarchy (that "closest to that aimed at in chemistry teaching" where "matter was conceptualized in terms of particle (or subparticle) systems and the relations between particles", pp.563-564) did not demonstrate a conception of matter which could explain all that was expected by age 16 . So even the most sophisticated conception uncovered was not a 'final stage' in terms of the intended target knowledge.

Although learning pathways should not be inferred from cross-sectional studies (as longitudinal research is needed to follow the actual trajectories learners' ideas take), the Renström et al. study suggests that the acquisition of particle ideas that match curriculum models may involve a considerable gestation. 


\section{Learning about particles in the English context}

The research findings discussed above derive from an international literature. In the UK, where the study reported here was undertaken, analysis of data from National Surveys carried out in the 1980s by the government's Assessment of Performance Unit (e.g. APU 1989âa) identified common misunderstandings of basic chemical ideas, including the application of basic particle models (Brook, Briggs \& Driver, 1984; Briggs \& Holding, 1986). Classroom-based case studies (Wightman et al, 1986) again found students having difficulty acquiring scientific meanings for particle ideas.

These studies were undertaken before a National Curriculum was introduced in England (henceforth ENC) that mandated the science to be taught during the compulsory school years (ages 5-16), and which provides the curriculum context for the study we report below.

Johnson (1998a, b, c, 2000a, b, 2005) undertook a detailed study of a group of students learning about basic chemical ideas in lower secondary science during the period 1990-1993. This coincided with the introduction of the ENC (Educational Reform Act, 1988; SI, 1989). Johnson's school science staff revised their lower school teaching scheme to meet the curriculum requirements (schools had previously had total freedom to select science content to teach, as discussed below.) This scheme was piloted with the new intake in September 1989, and the following year's intake included the class Johnson investigated for his study (Johnson, P. M., personal communication, $26^{\text {th }}$ October, 2007).

Johnson drew upon the Renström et al. model discussed above, and developed an analytical scheme for a 'basic' particle model suitable for the lower secondary years in relation to the teaching scheme being used in the study school (Johnson, 1998a). The basic particle model did not distinguish between molecules, ions, etc., and did not consider internal structure. There were four main stages in the analytical scheme Johnson adopted: where particle ideas were not used by students: where they referred to particles but considered them embedded in a substance; where they accepted the particles were the substance, but assigned them macroscopic properties; and where particles with one set of properties made up the substance and collectively gave it distinct macroscopic properties. 
Johnson (1998a) suggested that his findings could be seen in an optimistic light. Over the three years of lower school science there was evidence that most pupils made progress towards the target knowledge. This suggested that the particle ideas that did not match curriculum models were none-the-less acting as suitable intermediate conceptions on a conceptual trajectory towards understanding matching target knowledge (cf. Driver, 1989; Driver, Leach, Scott \& Wood-Robinson, 1994).

Despite his optimism, Johnson's results also showed that even in a teaching context carefully planned to support progression in this topic area, the acquisition of the desired level of understanding was developed slowly,

\begin{abstract}
Although many pupils remained in the same category for a pair of consecutive interviews, over the longer time span the evidence is that most of the pupils did change in their thinking, and with a considerable number moving to [the final] model.
\end{abstract}

Johnson, 1998a: 402

A little under half of the group had reached this 'particles are the substance, properties of state are collective' level in his final round of interviews (Johnson, 1998a: 402). Johnson suggested that intrinsic motion was a difficult idea for students to master, although they could progress to the final stage of his basic particle model without appreciating this. He also recommended that more emphasis should be placed on inter-particle attractions when teaching a basic particle model (see also Papageorgiou \& Johnson, 2005). Whilst acknowledging that generalization from a single school is unwise, Johnson recommended that,

it seems prudent to assume that it will take time for pupils to come to terms with the basic particle model. This might mean that the introduction of further ideas will need to be delayed.

Johnson, 1998: 410

Such 'further' ideas might include the distinction between different types of submicroscopic particles making up different materials (molecules, ions, etc.); the structure of atoms; the bonding and structure in different types of materials (salt, metal, sugar, water, etc). 
"In many ways, science teachers in the 1960 s and 1970 s were working within an educational free market. They were free, at least in principle, to choose from a range of syllabuses or, subject to constraints, construct their own courses and examine their own pupils for public certification."

$$
\text { Jenkins, 2004: } 37
$$

This situation changed dramatically with the introduction of the ENC (DES/WO

(1988; SI, 1989). Under the ENC, all State maintained schools were required to teach

all their students a broad and balanced science that was highly prescribed, and new

National Tests were introduced for all 14 year olds. Undoubtedly many students in

English schools were taught about particle theory prior to the ENC implementation,

but with the new curriculum came the requirement that all schools must teach these

ideas to all their students across the ability range in the lower secondary school.

In the ENC, particle theory is formally taught at lower secondary level, i.e. 'Key

Stage 3' (henceforth KS3, for 11-14 year olds). During this stage of schooling, 
schools are required to teach pupils: how the particle theory of matter can be used to explain the properties of solids, liquids and gases, including changes of state, gas pressure and diffusion (KS3-Sc3-1b, all curriculum references in this form are to sections of DfEE/QCA, 1999); how particle theory is used to understand the chemical elements (KS3-Sc3-1c), the nature of chemical change (KS3-Sc3-2g), and heat transfer (KS3-Sc4-5f).

At the time the research reported here was undertaken, the upper secondary level (Key Stage 4 or KS4, for 14-16 year olds), curriculum that most students ${ }^{\text {ii }}$ were required to follow included:

- a basic model of atomic structure (KS4-Sc3-1a-d);

- how this sub-atomic level of structure is used to explain the properties of different substances (KS4-Sc3-1g-k);

- how chemical change depends upon particle interactions (KS4-Sc3-1f);

- how reactivity depends upon atomic structure (KS4-Sc3-1e);

- how particle theory can be used to explain reaction rates (KS4-Sc3-3p);

- how atomic structure is the basis for systemizing a study of the chemical elements (KS4-Sc3-3b-c);

- particle models to explain nuclear radiation (KS4-Sc4-6a, c);

- particle models of electrical current (KS4-Sc4-1m, p).

Deleted: 'framework'

A key idea in the science teaching Framework

The ENC set out prescribed content that schools were required to teach, but individual schools maintained the responsibility for organising teaching and sequencing content. However, after a decade of English schools working with a prescribed curriculum, a revision of the ENC published in 1999 (DfEE/QCA, 1999) was followed by a series of major initiatives funded by the UK government intended to raise pupil attainment Deleted: A by offering schools guidance on how to implement the curriculum. 
This unit lays the foundation for subsequent work on particles. Pupils will have many opportunities in later units to try to explain phenomena in terms of particles, e. $\mathrm{g}_{\text {. }}$ dissolving in unit $7 \mathrm{H}$ 'Solutions', changes of state in unit 8I 'Heating and cooling', digestion in unit $8 \mathrm{~A}$ 'Food and digestion', crystal size related to rate of cooling in unit $8 \mathrm{H}$ 'The rock cycle', the behaviour of gases in unit 9L 'Pressure and moments'.

QCA, 2000: 1

A 'National Strategy' (initially called the 'Key Stage 3 Strategy', later re-branded the 'Secondary Strategy', and henceforth referred to as 'the Strategy') included a specific science strand. This strand, was piloted in the school year 2001-2, and then 'rolledout' nationally (Stoll et al, 2003). The output has included a good deal of guidance issued to teachers, organised around a published 'Framework for teaching science' (DfES, 2002, henceforth 'the Framework') in the three years of the lower secondary

Deleted: national

Deleted: strategy'

Deleted:

Deleted: (DfES, 2002) key stage (signified as years 7,8 , and 9 of the 11 years of compulsory schooling).

Whilst officially only a guidance document, the Framework - which was itself designed around the 'model' QCA Scheme of work - became the referent for a multitude of teacher development opportunities, guidance documents on aspects of pedagogy, and sample teaching resources issued to schools through the Strategy, and promoted through a national programme of teacher development courses (that all schools were given funding to access), which was in turn supported by the appointment of Strategy advisory teachers appointed in each area of the country. A central feature of the Framework was the identification of five 'key ideas' in science, to act as foci for teaching the subject. This could be seen as a response to common criticisms of the science curriculum as comprising too many topics (the recommended scheme of work for KS3 organises the curriculum into 37 discrete topics, see Colleague and Author1, 2005), which need to be passed over quickly rather than studied in depth (e.g. Millar \& Osborne, 1998). According to this recommended Framework: 
The five key scientific ideas that underpin the Key Stage 3 programme of study are: cells, interdependence, particles, forces [and] energy. It is important to introduce all five key scientific ideas early in Key Stage 3. Pupils need to develop their understanding steadily so that they can recognise, use and then apply each of the ideas in different contexts.

$$
\text { DfES, 2002, p.14 }
$$

The precise selection of 'key ideas' is open to criticism (Colleague \& Author1, 2005; Grevatt, Gilbert \& Newberry, 2007), but the presence of particles on any such list would seem essential (Author1, 2002a). Various examples are presented (DfES, 2002:14, 17, 18) to show where particle ideas may be applied "once each idea has been introduced in Year 7"' (p.14).

The approach recommended in the Framework is based on sensible pedagogic principles, i.e. that the key ideas are introduced early in secondary education, and immediately used in some explanations, then subsequently being applied widely in a Deleted: with the ideas range of contexts to provide further consolidation and reinforcement throughout the three years. The Framework offers teachers specific suggestions of where particle ideas should be revisited throughout the three years (DfES, 2002: 28).

Deleted: key stage Deleted: introduced

The Framework clearly sets out 'particles' as a key idea that should be met and applied by all students in lower secondary science, and where progression from simple to more sophisticated models is expected as the norm within lower secondary Deleted: figure science (see Figure 1).

Figure 1: The Framework for teaching all lower secondary

Deleted: pupils to use particle ideas

Teacher professional development materials issued as part of the Strategy, and intended to be used in all schools, spell out the degree of progression expected during lower school science, 
Particles is a key scientific idea which is explicitly taught for the first time at Key Stage 3 and permeates science at this age range and thereafter...When teaching about atoms, elements, molecules and compounds in Year 8 it is helpful to use a variety of visual and physical models to develop pupils' understanding...Teaching and learning in Year 9 about conservation of mass and how particles can rearrange is central to developing pupils' understanding of chemical reactions and equations.

DfES, 2003

\section{The Framework set out specific teaching objectives for the 'key ideas' in each of the years of lower secondary science (DfES, 2002). The teaching objectives relating to particles are shown in Figure 2. (The Figure omits objectives relating to the reactions and reactivity of metals included under 'particles' in the Framework that do not explicitly refer to particle models.)}

\section{Figure 2: Teaching objectives for the three years of lower} secondary science (from DfES, 2002: 28)

It is within this curriculum context that the study reported here was undertaken. The present research was timely, as a new programme of study for science within the ENC at KS4 (upper secondary level) was introduced in 2006, and a revised KS3 (lower secondary) curriculum is being introduced in 2008 (see the Discussion). In both cases the revisions amount to substantive redesigns, rather than peripheral modifications to the previous curriculum requirements.

Over a period of one-and-a-half decades, a highly specified science curriculum has been introduced, reinforced by National Tests, and then supplemented - first by an official model teaching scheme, and then by a detailed 'Framework' for planning and organising science teaching, supported by an extensive Strategy meant to inform pedagogy. Our study coincides with the end-point of this process of what (in the Deleted: national Deleted: tests Deleted: (at lower secondary level)

Deleted: framework' English context) amounts to an unprecedented attempt to regulate the teaching of science.

\section{An interview study exploring student explanations}

\section{Context}

The study reported here was carried out in the [blinded for review] area of England during the second half of the 2004-5 academic year (i.e. March-June 2005), The study

Deleted: a period of several months during spring 
was designed to find out how secondary age students would explain a range of demonstrations relating to phenomena commonly met in school science. We were interested to explore the ideas students would use in their explanations, and (of particular relevance to this paper) the extent to which they would draw upon particlebased explanations.

\section{Methodology}

Data were collected for this study using semi-structured interviewing techniques with secondary students. The choice of what is effectively a qualitative research technique was made because of the desire to investigate student thinking in depth, probing their own ways of describing and explaining phenomena (Author1 2006). Such idiographic approaches have long been recognised as necessary for fine-grained exploration of students' ideas (Osborne \& Wittrock, 1985; Pope \& Denicolo, 1986; Smith, diSessa \& Roschelle, 1993). Given this necessary decision, and the resource and practical implications of an interview study, it was not possible to set out to build a large and representative sample that could claim to survey students' use of particle ideas in the English context.

The use of simple demonstrations (e.g. mixing two liquids) is an example of a wellestablished type of protocol used in science education research, known as 'interviewabout-events' (White \& Gunstone, 1992). The demonstrations were carried out by the second author, and used as foci to elicit explanations. A repertoire of demonstrations was developed (detailed below), but as interviews typically lasted about 20-30 minutes (a reasonable time to maintain student interest and concentration), only a selection of demonstrations could be included in each interview. Audio recordings were made of the interviews, and these were later transcribed for analysis.

The intention was to explore student explanations in different 'science' contexts, where the idea of particles could be applied. The demonstrations were examples of physical changes, mixing (or not) and dissolving, and of chemical changes, and link to the teaching objectives in the Framework (DfES, 2002, see Figure 2). For example coloured and non-coloured solids were used to investigate dissolving (a focus of year 7 teaching objectives), Compressing air in a syringe directly links with a year 7 objective to teach why solids and liquids are much less compressible than gases, and 
$\underline{\text { the demonstration of spreading of food dye in water relates to another objective for }}$ year 7 to teach why diffusion occurs in liquids and gases. Teaching particle models of chemical reactions appears in both Year 8 and 9 objectives.

Similar phenomena have been used in previous studies: for example, Novick \& Nussbaum (1981), reported using air in a sealed syringe to investigate about air compressibility, Needham \& Hill (1987) reported using a copper sulphate crystal placed in water as an example of dissolving (we used potassium permanganate in the present study). Barker \& Millar (1999) used precipitation reactions, in order to examine students' ideas about chemical reactions.

The limitations of an exploratory study

Educational research has commonly been characterised as being of two main types, $\underline{\text { sometimes labelled as distinct paradigms (Gilbert \& Watts, 1983). These two camps }}$ are described in various ways such as positivist-interpretative or sometimes quantitative-qualitative, and may be seen as involved in competing and incommensurate forms of enquiry. However, within what might be termed a "postpositivist' view of research, such as that advocated by the US National Research Council (NRC, 2002), it is accepted that a broad range of methodologies (each having distinct strengths and weaknesses) can contribute to a programme of research. From this perspective, 'exploratory' studies are used when phenomena are complex or where a problem or context is novel, and 'confirmatory' studies are used to test specific hypotheses when distinct research categories (and instruments to gauge them) are available from previous studies (Author1, 2007).

$\underline{\text { As described below, we worked with a convenience sample. We looked to recruit a }}$ varied sample by including several schools and asking for volunteers across the ability range, but we cannot claim that our findings are strictly representative of the wider population. Our study is therefore exploratory, and a more extensive follow-up survey would be necessary to establish whether our findings are statistically generalisable. We describe the nature of our sample below, offering readers the opportunity to consider whether our findings can be considered relevant to wider contexts, i.e. reader generalisation (Kvale, 1996; Eybe \& Schmidt, 2001). We also
Formatted: Font:

(Default) Times, Complex Script Font: Times New Roman, Not Bold
Formatted: Complex Script Font: 10 pt, English U.S.

Formatted: Font:

(Default) Times, Complex Script Font: Times New

Formatted: English U.S.

Formatted: Font:

(Default) Times, Complex Script Font: Times New Roman, Not Bold 
argue below that the findings from our exploratory work age given credence by the outcomes of National Tests sat by all 14-year olds in England.

Deleted: II

Sample

Data were collected from 46 secondary students, from 5 schools (see Table 1). The

Deleted: was schools were co-educational state schools (three in the City of [blinded for review] and two in adjacent villages) where the teaching of the ENC was compulsory. The schools that were invited to participate in the study all had links to the Faculty of Education in [blinded for review], and were considered to offer examples of good practice in terms of teaching and professional development.

A desire to include students across a range of year groups and from several Deleted: institutional contexts was moderated by pragmatic concerns (relating to when school colleagues could host research visits). Students were volunteers, nominated by their class teachers as being willing to spend time being interviewed, selected from across the ability range.

Our decision not to limit the study to those students identified by their teachers as Deleted: more able was a principled one, in view of the common programme of study set out in the curriculum for all students. That is, whilst differentiation by outcome is recognised in the National Curriculum in terms of 'levels' exemplified by increasing degrees of sophistication in the thinking being demonstrated by students (DfEE/QCA, 1999, see the Discussion, below), learning about particle models is none-the-less prescribed for all students.

Interviewing only those learners offering their assistance was considered important both to ensure validity of responses (Stahly, Krockover \& Shepardson, 1999) and to meet ethical principles (Author1, 2002b; DiCicco-Bloom \& Crabtree, 2006), although this inevitably compromises the representativeness of the sample (Gao \& Watkins, 2002).

Table 1: The spread of students interviewed across schools and year groups 


\section{Data analysis}

There were two stages in the analysis of data. The first stage used an iterative opencoding procedure, similar to that reported by Renström et al. (1990) in their study

discussed above. Data were initially coded in descriptive ways, breaking up transcripts into basic units, before looking to develop theoretical categories that reflect ('emerge from') the data. This round of analysis provided insights into the way the students were constructing their explanations based upon a mixture of 'intuitive' notions and taught scientific concepts. The findings of this stage of the analysis (Author2, 2005; Author2 \& Author1, 2006) are not reported in depth here.

We then considered the specific question of the extent to which the student explanations drew upon the 'key idea' of particles, and whether particle-based explanations elicited matched the scientific models presented in the curriculum. The second stage of analysis involved classifying segments of interviews into a number of categories, in a similar manner to that used by Johnson (1998a) in his study discussed Deleted: of Deleted: our data above.

For this purpose we developed a four-fold classification scheme, to categorize the explanations given in each of the episodes:

$\mathrm{N}$ : no explanation offered

M: an explanation is offered, which does not call upon particle ideas (i.e. a 'macroscopic' or 'molar' level explanation)

P1: an explanation is offered in terms of particle ideas, but is not considered to offer a scientifically acceptable response (in terms of the models taught in the curriculum)

P2: an explanation is offered in terms of particle ideas, which is considered to be a scientifically acceptable response (in terms of the models taught in the curriculum)

Our scheme is similar (though simpler) to the models offered by Renström et al. (1990) and Johnson (1998a), but does not seek to offer fine graduations on student responses. For our present purposes all explanations which called upon particles, but 
which we judged to demonstrate alternative conceptions, were classified together without discriminating specific deviations from the models presented in the curriculum. The scheme will be illustrated in terms of illustrative examples of student responses in each of the classes of phenomena demonstrated.

We have analysed transcripts by episodes, where an episode reflects the recorded dialogue about a particular demonstration. As the examples we quote will suggest, some student comments could be considered ambiguous in terms of how they were using particle notions, so in making assignments we have attempted to interpret specific statements within the wider context of a students' comments within a particular interview episode. We have tidied extracts from transcripts to increase readability.

\section{Findings}

There were just over two hundred discrete episodes in the database, relating to five classes of phenomena: dissolving; changing state; mixing; chemical reactions; and immiscibility. We will briefly consider each of these classes.

\section{Explaining dissolving}

The demonstrations used here were: adding a pinch of table salt or sugar to tap water and waiting for it to dissolve, and asking about the possibility of separating the solution; and adding a crystal of potassium permanganate to water and waiting for it to dissolve to give a strongly coloured solution.

Table 2: Classification of students' explanations of dissolving

There were 79 interview episodes where students were asked to explain aspects of dissolving (see Table 2). In 7 of these episodes the students were not able to offer any kind of explanation (category $\mathrm{N}$ ). Of the other 72 episodes, 22 were categorised as $\mathrm{M}$. An example of a student response categorised as $\mathrm{M}$ came from a year 8 student from school 3 (designated student 5, S5), who suggested that when salt was added to water:

S5: The water is kind of making [the salt] smaller and smaller 
I (Interviewer, Author2): How is it that the water makes it become smaller and smaller?

S5: Is there something in the water that makes it, that reacts with the salt, [something that] kind of just makes it smaller and smaller?

I: What do you mean by reacting?

S5: When it is salt and sugar and stuff I don't know, it makes the salt melt, but like in a kind of way, not with the heat. Just eventually it will just dissolve, you can still taste in the water, but you cannot see it - it is invisible, but it is still there.

We see that S5 refers to the observable phenomena of grains getting smaller during dissolving. She is aware that although the solid seems to disappear, it is still present in a sense, and can be detected in the taste of the solution. However she does not explain this with particle ideas. In particular she refers to a 'reaction' and to 'melting'. From her observations, dissolving is not so different to chemical reactions (where substances 'disappear') or melting (where a solid substance becomes a liquid form of the same substance). In scientific terms these are very different processes to each other, and to dissolving: something that is very clear when these processes are modelled in particle terms, but less obvious from simple observation.

Another example of a response categorised this way was elicited from a Y10 student from school 5, designated S34. Here we see S34 use a suitable technical term, 'diffusion', to explain why the colour of the potassium permanganate spreads through the water. However, he explains this in terms of the solid being 'softened' by the water, rather than drawing upon a mental model of what was happening at a particle level.

I: Observe what happens. Describe and try to explain, what is happening in there? S34: It's diffusing, I think.

I: How do you think this happens?

S34: Cause the water like wets it, then it like spreads. The crystal is hard and if you wet it, then it is soft and spreads. 
22 of the episodes were categorised at level M (Table 2).

Even when students do refer to particle models, they may not be able to apply them in a scientifically acceptable way. S17, a Year 9 student from school 3, provides an example of a student response categorised as P1:

I: I'm going to put some tap water here, and what I have here is some potassium permanganate. I want you to explain me what is happening and why it is happening that way.

S17: It's probably reacting into the water

I: What do you mean by reacting?

S17: Well, [hesitation and false starts] like the different particles are joining together, like, making a new thing. I don't know.

So S17 refers to particles, but can only offer a vague explanation in terms of what is happening at the submicroscopic level. As another example, consider the comments of a Y9 student from school 3 when asked if the dissolved salt could be recovered from the solution. $\mathrm{S} 22$ reports correctly that she could "evaporate the water", "because the salt particles are too heavy and they won't be carried, they won't evaporate up, they'll stay there". This is perhaps a creditable attempt at a response. However at the scale of molecules and ions, the weight of the particle is not the major consideration. This seems to be an example of the very common phenomenon of students assigning macroscopic properties to the particles, and then using these assigned properties to explain macroscopic events. 36 of the episodes were categorised as P1 (Table 2).

Other students had made more progress in developing their understanding of particle models, to a point where their explanations drew upon particle ideas in ways that better fitted the ideas taught in the secondary curriculum. 14 episodes were categorised as P2. An example of a student response categorised as P2, was a Y9 student from school 2, S12:

I: So, what's happening in there and why do you think it's happening that way? 


\section{S12: It's dissolving in the water}

I: What do you mean by dissolving?

S12: The chemicals, I mean the particles in the potassium perman-, whatever, is sort of mixing in with the particles in the water, but they are not sort of joining, just mixing. Eventually the water will be all purple

I: Why is that?

S12: Because the particles sort of, spread as far as they can, they will all be mixed with water.

So S12 was able to relate the observable phenomena of the spreading colour to both the concept of dissolving and an acceptable scientific model she had learnt about how particles of substances become mixed when a solute dissolves in solvent. One Y10 student from School 5, produced a 'P2' category explanation of salt dissolving, that included reference to the idea of a saturated solution explained in particle terms:

S39: The salt is soluble and the water takes part of the salt and then the particles mix together with the water, but then when there is too many salt particles in there, the salt could stop breaking up and there would be salt granules left at the bottom. If you heat it up, it might speed up, leaving no granules. But if you keep doing it for a very long time, eventually you couldn't dissolve any more salt into the water, it would be left at the bottom.

This is an example of effective coordination of the use of particle models with scientific descriptions of processes at a macroscopic level. This is the level of knowledge and understanding sought in secondary science teaching, but which many of the students interviewed did not demonstrate.

\section{Explaining physical changes:}

The same categories of responses were used to analyse the other interview episodes, and a similar range of responses was found. So to explore student thinking about physical changes (i.e. changes of state, or of state functions such as pressure - the problematic nature of the physical-chemical change distinction is considered in the 
Discussion below), demonstrations were used of evaporating water, stretching a small piece of metal and compressing air in a sealed syringe. Students were also asked what happens when water freezes, why it is that ice floats in water, and how we can smell an odour some distance from its source.

Table 3: Classification of students' explanations of physical

changes

The database contained 41 interview episodes relating to this class of phenomena (Table 3). There were only two episodes where the student was unable to offer an explanation $(\mathrm{N})$, and only five where particle ideas were not used (M). An example of such a response was that of student S2, a Y7 student from school 1. She explained that when water is heated "you get bubbles, it boils", and that before it boils "it gets hotter and hotter and steam comes out and then it starts to bubble". A Y8 student from the same school, S11, provides an example of an explanation referring to particles, but not in a scientifically acceptable way (i.e. P1). According to S11, "The water would evaporate, the particles expand, but I'm not really sure how". He thought that "if you heat water then the particles...like grow bigger", although he admitted some doubt about the process.

There were 10 episodes categorised as P1, whereas most (24) of the episodes relating to this class of phenomena were categorised as P2. For example, S34, a Y10 student from school 5 freely referred to molecules, and described how when water was heated "they evaporate, go into the air, join the air, until they cool down and condense...it's like individual particles split up, instead of being a group with lots of them, you have individual ones". Although technically the molecules should not be said to evaporate and condense (these terms describe behaviour at the macroscopic substance level), S34 appeared to have well developed mental models of phenomena in terms of particles. S45, a Y11 student from school 1, also explained: "they [water molecules] are still the same compound, it's still $\mathrm{H}_{2} \mathrm{O}$, but in a different physical state [where] they have less attraction to the other particles in this substance". 
1

2

3

4

5

6

7

8

9

\section{Explaining mixing}

Another context used was that of mixing. The demonstrations used here included adding equal volumes of ethanol and water and asking why is it that the total volume was not conserved (i.e. due to the strong interactions between the different molecules), and adding a few drops of food dye to tap water.

\section{Table 4: Classification of student explanations of mixing}

There are 32 episodes categorised for this class of phenomena, including one where no explanation was provided (see Table 4). 13 of the responses did not refer to particle ideas and were classified as M. For example S9, a Y8 student from school 3:

I: now that you have seen that [the total volume] has changed, how would you explain it?

S9: It might have air trapped in it, that was trapped in the measurement thing you had and it lost its air while being transferred.

[The mixture is shaken, and the volume decreases further.]

S9: You get rid of the excess air by shaking it. It is bubbling now so it is the air.

S9 explains the non-conservation of volumes in macroscopic terms, arguing that ethanol and water have air trapped in them, which is released on mixing - a conjecture apparently then confirmed when bubbles form as the mixture is shaken. S9's suggestion has merit. Air dissolved in water may be 'degassed' when another substance dissolves. This can be demonstrated in the school laboratory, but requires carefully setting-up and close observation (Author1, 1985). A simple explanation would consider the particles of the new solute fitting between water particles where Deleted: concern the air particles had been. Despite the merit of her idea, S9 did not attempt to offer any kind of particle-based explanation.

15 of the episodes were categorised as level P1. So S23, a Y9 student from school 5, offers an explanation of food dye mixing with water that refers to particles, without doing so in a scientifically acceptable way. She talked of how the food dye "would merge with the water particles". This could just be a poorly phrased attempt at 
explaining mixing at the particle level. However, when making a comparison with dissolving salt, she suggested,

"it's slightly different since the salt particles are solid and the dye is a liquid. The dye is slowly reacting but in a slightly different way. They both merge, kind of together you can see the green dye but you can't see the salt without a microscope".

She thought that "with a magnifier you could see, but you would see the dye merged with the water". There are a number of technical errors here - confusing mixing with a reaction; considering particles to be solid or liquid (so that salt particles are judged 'solid' in the solution), and expecting the 'merging' of food dye with water to be on a scale that is visible if magnified.

By comparison, a Y10 student from the same school, S39, seemed to appreciate how the particle level mixing provided the macroscopic phenomena: "particles of the food dye are going to spread into the particles of the water and it is going to mix colour. It's different particles, in between the water, and then the food [dye] colour. You can't change the colour of the water particles". This was one of only three episodes categorised at level P2.

\section{Explaining chemical reactions}

Another context used in the interviews was that of chemical reactions. The demonstrations used here included: a precipitation reaction (silver chloride formation from sodium chloride and silver nitrate solutions) and a neutralisation reaction (diluted sulphuric acid and sodium hydroxide reaction in the presence of an indicator to indicate $\mathrm{pH}$ ). There were 26 episodes for this class of phenomena, and there were no examples where students did not offer an explanation (see Table 5).

Table 5: Classification of student explanations of chemical reactions

Again some students did not seem to refer to particle ideas in their explanations (i.e. eight episodes were categorized M, see Table 5). So a Y8 student from school 3, S5, suggested "some kind of reaction because it changed colour", but could offer no further explanation beyond noting that the immediate reaction showed "they've must 
[have] like mixed immediately". When prompted to talk about the phenomenon in particle terms, she declined: "oh, no, I'm not doing that". By comparison a Y9 student from school 2, S13, was happy to talk about particles, but explained the precipitation reaction in terms of the original reactant salt being "still in there pushed down by the water molecules, but now it's joined by these molecules". This response was one of 14 categorized as P1. Explaining chemical changes requires a more sophisticated type of particle model than suffices for explaining phenomena such as mixing and changes of state. There were only 4 episodes categorised as showing this higher level of understanding (P2), such as the Y8 student from school 3, S9, who described how "the silver particles in the silver nitrate [are] reacting with the salt and creating something new in the reaction". This is not a thorough description in terms of particles, but acknowledges that a new substance results from interactions at particle level. He recognised that the precipitate (which is initially suspended in the reaction solution, and may take some time to sediment out) was not still part of the solution itself: "because the white stuff almost seems as if it is kind of a solid, within a solution".

\section{Explaining non-mixing}

The final class of phenomena demonstrated concerned situations when mixing did not take place, such as an insoluble solid in water (sand was used) and immiscible liquids (shown by adding oil to water). There were 24 episodes relating to this class of phenomena, and only two examples of students being unable to offer some kind of explanation (Table 6).

Table 6: Classification of students' explanations of non-mixing

Over half (13) of the episodes produced explanations that were categorised as not involving particle ideas (M, see Table 6). An example would be that of a Y9 student from school 4. When asked about oil added to water, S29 correctly observed that "it just floats", something he attempted to explain in terms of trapped air: "when the oil was added, there was air in the bubbles, so when they hit they're just absorbing all the air from the bubbles and since they are in the water they can't get up". An example of one of the eight episodes categorised as P1 would be from another Y9 student, S12, from school 2, who did use the idea of particles when explaining why sand, unlike 
salt, was insoluble. She thought this was because "the particles are too big to dissolve in the water". Finally, the only example of a student explanation that was considered to use particle ideas in a scientifically satisfactory way (i.e. classified P2) was provided in an interview with a Y11 student from school 1. Student 43 suggested: "maybe, I'm going to be wrong here, I'm going to say the particles are not attracted to each other, because most particles have a charge on them, and maybe, like, maybe the oil is not the same charge as the water". The explanation is tentative, and technically incorrect, but was judged to apply the taught curriculum models.

\section{Discussion}

Considering all five classes of phenomena demonstrated, there are 202 episodes in the database (see Table 7), and students offered explanations in 190 episodes (i.e. 12 were categorised as $\mathrm{N}$ ).

Table 7: The overall classification of interview episodes

Just under a third of the explanations offered were framed purely in macroscopic terms (61 categorised as M). This means that in nearly two thirds of the episodes, students $d i d$ offer explanations that drew upon the 'key idea' of particles. However, in most of these cases ( 83 categorised as P1) the explanations offered were not acceptable in terms of the scientific particle models taught in school science. So scientifically acceptable particle-based explanations were offered in just over onefifth of the episodes recorded (46 categorised as P2). This distribution is shown graphically in Figure 3 . ideas in student explanations

The only class of phenomena where the students in our sample were generally able to offer acceptable responses was that of physical changes (see Table 3). This is not obviously the simplest class of phenomena to explain, and it may seem odd that students seemed to find mixing (for example) a more challenging class of phenomena to explain with particle ideas. However, this finding may relate to how the particle model is commonly introduced in the context of teaching about the states of matter (see figure 1) - and then subsequently applied in various other contexts. 


\section{Limitations of the study}

There are a number of significant limitations to the present study. We interviewed a convenience sample of secondary students from a small number of schools in one geographical area. The nature and size of the sample do not allow us to offer views about school differences, and we clearly do not claim that the sample can be seen as fully representative of secondary students following the ENC, even in this one geographical area. Although our sample is spread across the secondary age range (see Table 8), the nature of the sample does not allow us to make reliable comparisons between year groups. The timing of our study is also significant here, undertaken during the third year of the Framework initiative. We would expect the influence on students in years 10 and 11 to be less, as they will have started their secondary education before the Framework was recommended.

Table 8: Classification of interview episodes by year group

Deleted: II

Practical limitations of the time pupils were available for interviews meant that a subset of phenomena was explored in each interview (typically four different demonstrations per interviewee). Although the nature of the interviews gave every opportunity for students to explain their ideas, we can not be sure we accessed their most sophisticated thinking, and it is possible we may sometimes have misinterpreted their intended meaning (especially as our concern was the nature of their conceptions, regardless of technically correct language).

\section{Characterising the instructional context}

In the Introductory sections to this paper we described the Curriculum context in England in terms of the extensive culture of 'guidance' offered to schools to inform classroom teaching. In terms of official intentions, teaching about particle ideas is a central focus of lower secondary science, featuring in yearly teaching objectives, and explicitly linked to many of the prescribed topics.

It is recognised that curriculum reform is a slow and complex process that can be impeded, frustrated or misdirected by a wide range of factors (e.g. Anderson, 1996). Whilst English schools are required to teach the prescribed curriculum, they have flexibility in responding to curriculum 'guidance' such as the Framework (DfES, 2002) and other outputs from the Strategy. 
The five schools where our data were collected demonstrate this, so that the individual departmental schemes of work reflected, but did not necessarily directly adopt, the full model scheme issued by the curriculum authority (e.g. QCA, 2000). One of the five schools where we collected data reported that they did not explicitly use the Framework (DfES, 2002), or any other Strategy resources (despite schools being given funding resources to access the associated training). However, this school had adopted a commercial teaching scheme (called 'Framework Science') claimed by its publishers to be "perfectly in line with the approach and content of the Framework and QCA Scheme of Work" (http://www.oup.com/uk/catalogue/?view=oxed\&ci=9780199148967, accessed 14/01/2008). This suggests that some of the influence of the government initiatives may be indirect: whilst some individual schools may believe they have good reasons not to adopt government advice on pedagogy, market pressures nonetheless ensure that schemes available from commercial publishers are presented as fitting the current guidance.

The other schools involved in the study used commercial teaching schemes that could be considered to be modified versions of the recommended model. These schools engaged with the Strategy programme of teacher support for the recommended Framework (DfES, 2002). The (then) Head of Science in one of the schools described how departmental staff had undertaken "extensive training in all aspects of the KS3 Strategy" which was considered to have "had a big impact on the achievement of our pupils and improving standards".

The non-mandated nature of official 'guidance'; the tendency for most schools to wish to show they have been following what is set out as 'best practice'; and the indirect ways in which such officially sanctioned advice can influence practice make it difficult to establish a clear picture of the precise influence of the government initiatives on the learning of students. Observing the extent to which teaching actually adopted the recommended approaches was beyond the present study. It seems reasonable to assume that actual classroom practice in England reflects government 'guidance' to differing degrees, which seems to be the case in the schools involved in the present study

Deleted: II

A larger-scale, more representative National survey would be needed to check the generalisability of our findings. indicators Any such survey would need to be carried out before the start of the 2008-9 school year, for it to explore the particular curricular context we describe above. However, we consider our results are indicative of what would likely be found in a more systematic survey. 


\section{Indications from the National Testing regime}

Our findings from a modestly-sized convenience sample of learners, drawn unevenly from a small number of schools in one locality in England, would best be considered as 'suggestive'. We consider the possible implications of our own results below, but acknowledge that readers should bear in mind the limitations of our sample.

National surveys of student attainment in science were undertaken in the 1980 s by the Assessment of Performance Unit (APU, 1989b) - a section of the government education ministry - providing National figures on student understanding of key areas of science (e.g. APU, 1989a) and providing useful information on student understanding about such areas as basic particle theory (Brook, Briggs \& Driver, 1984). However, the surveys were discontinued before the introduction of the National Curriculum and the subsequent increasing prescription of teaching approaches by successive UK governments, leaving gross outcomes on National Tests and school-leaving examinations as the main indicators available to government and others to monitor the effectiveness of curriculum policies and pedagogic advice

The National Testing regime reporting on student attainment at age 14 (at the end of the lower secondary 'key stage') is based around the assignment of students to 'levels' of attainment. Although the reported Test statistics only offer an overall view of student performance, reports produced for teachers offer some more specific indications of areas of weakness,

"The application of particle theory to pressure in liquids and gases is not well understood. ... pupils were unable to explain what happens to the spacing between particles when liquids and gases are put under pressure. In 1999, pupils had similar difficulties in explaining how air particles in a tyre exert a pressure"

QCA, 2001: 11

"[most pupils] could draw the arrangement of particles in a gas, but only a few recognised that when water vapour is condensed into water the gas molecules which are well separated come into loose contact with one another...pupils had to say what would happen to samples of copper sulphate solution left in an open and in a covered dish. Many pupils did not recognise that evaporation would be faster from the open dish because freely circulating air would allow the vapour particles to diffuse away easily."

QCA, 2003: 29-30 
"make links between the nature and behaviour of materials and the particles of which they are composed. They use the particle model of matter in explanations of phenomena. They explain differences between elements, compounds and mixtures in terms of their constituent particles"

DfES/QCA, 1999

Only at level 8 are students expected to be able to "use the particle model in a wide range of contexts". So-called 'exceptional performance' beyond level 8 is typified by $\underline{\text { students who "use particle theory in a wider range of contexts, recognising that }}$ differences in the properties of materials relate to the nature of the particles within $\underline{\text { them" and who understand how the particle model can be used in explaining physical }}$ phenomena such as how sweating causes cooling (DfES/QCA, 1999).

Students are assigned an overall level for their performance in the National Tests. Deleted: : According to government statistics (DfES, 2006), National Testing in 2006 showed that $26 \%$ of students were assigned Level 6 and $15 \%$ attained level 7 (the highest level reported for this age group). The percentage of students attaining level 6 or above had not exceeded $40 \%$ in any of the previous 11 years of National Testing.

So by the end of KS3, about three-fifths of students are at level 5 or below. To the extent that levels assigned in National Tests can be considered to be reliably judged against the published level descriptors, it would seem that being able to apply the particle ideas taught to all is a characteristic expected of only a minority of students. This national picture lends some credence to our own findings (see Figure 3 and Table 7) as potentially relevant to the National context. 


\section{Familiarity without scientific understanding}

In our study we found that a majority of students were familiar enough with the concept of particles, and were generally happy to talk about phenomena in these terms. It seems that in the contexts of the then extant version of the ENC it was not the case that most students failed "to invoke atoms and molecules as explanatory constructs" (Hesse \& Anderson, 1992: 277).

Yet there was limited appreciation of the way that scientists use particle models to explain the properties of materials in terms of the distinct conjectured properties assigned to the molecules, ions and so forth. So where students did call upon particle ideas, they commonly assigned particles the macroscopic properties to be explained, as has been noted in previous studies (e.g. Author1, 2001). So our study reflects the findings reported in the literature reviewed earlier (Nussbaum \& Novick, 1982; Ault et al, 1984; Ben-Zvi et al, 1986; Briggs \& Holding, 1986; Wightman et al, 1986; Renström et al, 1990; Griffiths \& Preston, 1992; Author1, 2001), showing that even when students use particle ideas, they have considerable difficulty in doing so in scientifically accepted ways.

Our sample comprises students prepared to talk to us about their ideas from a number of secondary schools that we know to be strongly committed to teacher development and student achievement. So although our study does not form a representative survey of secondary students, we do consider our findings suggestive, indicating that there continue to be widespread difficulties in learning particle ideas in secondary science, despite the government attempts to support and direct teaching in this topic. We conclude that the curriculum guidance for those teaching the ENC (DfES, 2002,

Deleted: s 2003) has done little to change student understanding in this area since Johnson's study (1998a).

\section{Reflections on the curriculum context}

The approach recommended in English secondary schools is an early introduction of the key ideas, and then regular revisiting in a range of contexts to reinforce,

consolidate and develop learning (DfES, 2002, pp.18-19 - see Figure 1). We consider

Deleted: figure this approach to be a sound response to some aspects of student learning difficulties in this topic, but that, critically, it does not of itself address specific research findings. 
There seems little doubt that particle models used in science are highly abstract, and clearly unfamiliar in terms of everyday experience, and these two factors act as potential 'learning impediments' in the topic. The official curriculum guidance would seem an appropriate way to ensure that students develop familiarity with basic particle ideas. The students in our sample were indeed largely familiar with particle ideas and generally confident enough in their knowledge to make efforts to use them. In some cases the recommended teaching approach appeared to be reflected in student thinking. S23, a Y9 student from school 5 reported that the particles idea "makes sense" to her, as "you learn it from young and then when you get older they explain it more and more". However a Y10 student from the same school, S35, whilst acknowledging his familiarity with particles, did not see how particle ideas could help him understand phenomena: "sometimes you learn it because you have to learn it, but you don't understand it".

Such a response is not surprising in view of the findings of previous research. Studies of students' thinking in this area have repeatedly shown that many learners can readily adopt the idea of everything being made of particles, and are often happy to discuss phenomena in these terms. Unfortunately, however, this research also shows that aspects of the scientific models are not just unfamiliar to learners but counterintuitive - for example the idea that there is nothing between the particles in a hard solid, and that these particles can themselves be considered largely 'empty' space.

We do not wish to be over-pessimistic here. With Renström et al, we recognise that many learners can and do move through a succession of understandings that progress towards scientific models. Johnson's research suggests that where a basic particle model was presented early in lower secondary science, and revisited and developed, students could make significant progress over a three-year period.

Unfortunately, one key recommendation from Johnson's work has not been taken-up in the English curriculum. Particle ideas are revisited regularly in the English scheme, but where Johnson warned that students had to have time to master the basic particle model, lower secondary students in England are also expected to progress to more complex models that can explain the atomic basis of the elements, and the nature of chemical changes. This is presumably seen as an imperative in view of the work particle theories are expected to do by the end of compulsory schooling. Yet in 
The heart of the cultural contribution of science is a set of major ideas about the material world and how it behaves, such as the particle model of matter... It follows that these ideas and themes should be prominent within the science curriculum.

(Millar \& Osborne, 1998: §5.2.1)

If particle ideas are to remain central to the curriculum for all learners then our study suggests that current teaching approaches will leave many students confused. Instead more effective pedagogy needs to be developed.

Like Johnson before us, we wish to remain optimistic. Renström et al's (1990) work suggested that common alternative conceptions of particles could fit within a conceptual trajectory leading towards target knowledge and understanding. Johnson 
(1998a) showed that at least part of this model does represent a progression pathway at lower secondary level. The key problem seems to be the rate at which students progress through this pathway, which for many students is insufficient to allow a suitable 'basic' particle model to be developed early enough to provide robust foundations for further learning (about atoms, molecules, ions etc.).

The same problem seems to recur among the minority of students who are able to successfully demonstrate this progression during the compulsory school years, when they meet orbital models of the atom in college courses (Author, 2004). The Deleted : educational challenge, then, is to accelerate student progress through the sequence of conceptual models used in school and college science.

The Framework used in lower secondary education in England (DfES, 2002), which we have characterised as early introduction followed by frequent review, does not seem to meet this challenge. Whilst the sequencing of content may appear logical to subject experts, it fails to appreciate the complexity of the material presented from the perspective of most students' prior knowledge (Johnstone, 2000; Author1, 2002).

As one example, the Framework (DfES, 2002) recommends that teachers use a simple particle model to explain solution phenomena such as how rate of dissolving depends on temperature and saturated solutions in the first year of secondary school. The assumption seems to be that dissolving is a straightforward phenomenon when considered in particle terms. However students' explanations confusing dissolving with chemical reaction, reported above, act as a useful reminder of how even such a supposedly 'simple' phenomena can be understood at different levels of complexity. This class of 'physical' change involves the breaking and formation of bonds between particles (usually considered characteristic of 'chemical' changes), and in the case of ionic solutes, indeed, the breaking of strong chemical bonds (Author 1, 2002).

It is of note in this particular context that one of the yearly objectives listed in the Framework under the key idea of particles (see Figure 2) is to teach year 9 pupils to "identify evidence which indicates that a chemical reaction has taken place, such as the association of energy transfer with chemical change". This macroscopic indicator links to bond breaking/formation, and also to the entropy changes associated with mixing, cystallisation/precipitation, solvation etc. Perceptible energy transfers can

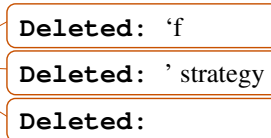


occur when ammonium salts dissolve, when oleum is mixed with water, or when

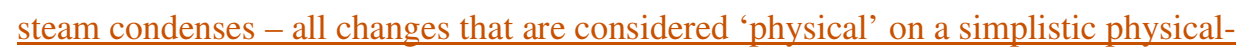
chemical changes dichotomy. Our feeling here is that the designers of the Framework (DfES, 2002) have failed to fully consider the teaching and learning implications of the objectives that set out target knowledge for all 14 year-olds in England.

We suspect that an approach drawing more heavily upon well-developed constructivist principles (Author1, 2006) might have more success. If students are constructing their understanding of 'particles' such as molecules and ions on the basis of their knowledge and experience of familiar 'particles' such as grains and specks, supported by concrete models (Harrison \& Treagust, 1996) that are inevitably fabricated from macroscopic materials, then it is not surprising that they are commonly missing the major ontological distinctions so central to the particle theories of science (Author1, 2001). However, we suspect that students may well have other conceptual resources (Hammer, 2004) that are more suitable for developing appropriate (i.e. scientific) notions of particles. We are encouraged by the findings of Ault, et al (1984) who reported that understanding about molecules evolved more rapidly from a rich conceptualisation, even when this included a range of idiosyncratic 'alternative' conceptions.

Our analysis of students' explanations identified a number of apparently intuitive ways of thinking about phenomena at the level that diSessa (1993) has described as 'phenomenological primitives' (Author2, 2005; Author2 \& Author1, 2006). DiSessa (1993) suggests that the human conceptual system uses a wide range of these 'pprims', which operate in perception to recognise phenomena in terms of basic patterns. DiSessa described p-prims as "primitive elements of cognitive mechanism as atomic and isolated a mental structure as one can find" (p.112). Where conceptions are specific notions that are of the form of propositions ('giraffes have long necks because their ancestors had to stretch for juicy leaves', 'inert gases do not react because they have stable electronic configurations', 'the sun pulls the earth more than the earth pulls the sun'), p-prims are primitive in the sense of acting at an early (preconscious) stage of cognition, and "act largely by being recognised in a physical system or in the system's behaviour or hypothesized behaviour" (diSessa, 1993: 111), that is by identifying phenomena as matching common general patterns. 
In effect they provide a repertoire of fundamental cognitive elements from which our mental models of the world are constructed. From this perspective, teaching can in principle take advantage of p-prims by channelling students towards the most productive available ways of perceiving new ideas.

Whilst this must at present be considered a tentative suggestion, we do feel there should be further research to explore the potential of this approach. If progression through a sequence of models could be guided by linking with basic intuitions about the world, then pedagogy could indeed be developed to accelerate learning about particles during secondary education (Author 1 , in press).

\section{Conclusions}

We have investigated the extent to which students could explain basic physical and chemical phenomena using particle ideas. This is an important focus because the particle concept is absolutely fundamental to understanding much of modern science, but previous studies have repeatedly demonstrated that this topic leads to such considerable learning difficulties that students frequently develop their own alternative conceptions inconsistent with the scientific models. This topic therefore offers a significant challenge to those designing science curricula and teaching schemes.

The English curriculum at the time of our study (DfEE/QCA, 1999) has provided an opportunity for exploring student thinking in an educational context where particles have been given particular emphasis in secondary science. Curriculum guidance had identified 'particles' as one of five 'key ideas' which should be used to organise and structure learning in lower secondary science (DfES, 2002). There had been considerable investment in supporting teachers to adopt such recommendations in terms of professional development and the dissemination of teaching and guidance materials (e.g. DfES, 2003).

Despite this, the present study found that most students in our sample were not able to use the particle model to provide explanations that matched scientific thinking. If our findings from a convenience sample of secondary students reflect the national 
situation, then this approach to teaching about particles in English secondary schools does not offer a satisfactory solution to this educational problem.

There already exists a good deal of research that indicates why this is a challenging topic, and where students commonly 'go wrong'. This study suggests that the approach of early introduction of particle ideas, followed by frequently revisiting the concept to explain a wide range of contexts does seem to lead to many students using particles as an explanatory device in science, but does not seem to overcome the wellrecognized problem that students commonly misunderstand and misapply particle ideas.

Given that the curriculum context of our present study is one where extensive guidance on this topic is provided to support teaching (DfES, 2002, 2003), it might be considered potentially a 'best case' scenario. Although our findings suggest that among our modest convenience sample the approach used in the English Strategy has Deleted: s not facilitated most students developing appropriate particle models, it seems likely that progress towards a 'scientific' understanding of particle models will be even slower in many other contexts where basic particle theory is introduced later or there is less emphasis on opportunities to apply and consolidate learning. This certainly seems to be the case, for example, in Sweden where a much less prescribed curriculum allows teachers much more flexibility in when and how to introduce these ideas (Colleague and Author 1, in press).

Whilst our findings suggest the strategy for teaching about particles in the English context has not been entirely successful, we do not see this as surprising, nor a reason for totally abandoning the approach. Our argument here is not that attempts to guide teachers in this area cannot be effective. New teaching approaches need to be carefully planned and piloted, and then properly evaluated once teachers have become $\underline{\text { familiar and confident in the new approaches. Optimum approaches are unlikely to be }}$ found immediately, and evaluations should inform cycles of modification and further evaluation. In particular, such approaches must be based on more sophisticated research-informed pedagogy. We have tentatively suggested one direction such research-based curriculum development might take.

$(12457)$

Deleted: Rather, we argue that guidance

Deleted: developed that is

Deleted:

Deleted: II (9409) 
Acknowledgements: Thanks are due to the [blinded for review] and to [blinded for review] for offering the second author a study visit that allowed her to undertake the fieldwork. The authors are grateful to the teachers in the local schools who organized research visits and identified students prepared to be interviewed. 


\section{References}

Anderson, R. D. (1996). Study of Curriculum Reform. Washington D C: U S Department of Education Office of Educational Research and Improvement.

APU (1989a). Science at Age 13: a review of APU survey findings 1980-84. Assessment of Performance Unit, London: HMSO.

APU (1989b) National Assessment: The APU Science Approach, Assessment of Performance Unit, London: HMSO

Ault, C. R., Novak, J. D., \& Gowin, D. B. (1984). Constructing Vee maps for clinical interviews on molecule concepts. Science Education, 68 (4), pp.441-462.

Barker, V. \& Millar, R. (1999) Students' reasoning about chemical reactions: what changes occur during a context-based post- 16 chemistry course? International Journal of Science Education, 21 (6), pp. 645-665.

Ben-Zvi, R., Eylon, B-S., \& Silberstein, J. (1986). Is an atom of copper malleable? Journal of Chemical Education, 63 (1), pp.64-66.

Briggs, H. \& Holding, B. (1986). Aspects of secondary students' understanding of elementary ideas in Chemistry, full report. Leeds: Children's Learning in Science Project, Centre for Studies in Science and Mathematics Education, University of Leeds.

Brook, A., Briggs, H. \& Driver, R. (1984). Aspects of secondary students' understanding of the particulate nature of matter. Leeds: Children's Learning in Science Project, Centre for Studies in Science and Mathematics Education, University of Leeds.

DES/WO (1988). Science for ages 5 to 16, London/Cardiff: Department for Education and Science/Welsh Office.

DfEE/QCA (1999). Science: The National Curriculum for England, key stages 1-4. Department for Education and Employment/Qualifications and Curriculum Authority.

DfES (2002). Framework for teaching science: years 7, 8 and 9, Key Stage 3 National Strategy, Department for Education and Skills.

I DfES (2006). National Curriculum Assessment at Key Stage 3 in England, 2006 (Provisional), Department for Education and Skills, release SFR 34/2006, dated 13 September 2006.

DiCicco-Bloom, B., \& Crabtree, B. F. (2006). The qualitative research interview. Medical Education, 40, 314-321.

diSessa, A. A. (1993). Towards an epistemology of physics. Cognition and Instruction, 10 (2\&3), pp.105-225.

Driver, R. (1983). The Pupil as Scientist? Milton Keynes: Open University Press.

Driver, R. (1989). Students' conceptions and the learning of science. International Journal of Science Education, 11 (special issue), pp.481-490. 
Driver, R., Leach, J., Scott, P., \& Wood-Robinson, C. (1994). Young people's understanding of science concepts: implications of cross-age studies for curriculum planning. Studies in Science Education, 24, pp.75-100.

Education Reform Act (1988). London: HMSO.

Eybe, H. \& Schmidt, H-J. (2001). Quality criteria and exemplary papers in chemistry education research, International Journal of Science Education, 23 (2), pp.209225.

Feynman, R. P., Leighton, R. B. \& Sands, M. (eds.) (1963). The Feynman Lectures on Deleted: II Physics, Volume 1. Reading, Massachusetts: Addison-Wesley Publishing Company.

Gao, L., \& Watkins, D. A. (2002). Conceptions of teaching held by school science teachers in P.R. China: identification and crosscultural comparisons. International Journal of Science Education, 24(1), pp. 61- 79.

Georgousi, K., Kampourakis, C. \& Tsaparlis, G. (2001). Physical-science knowledge and patterns of achievement at the primary-secondary interface, part 2: able and top-achieving students. Chemistry Education: Research and Practice in Europe, 2 (3), pp.253-263.

Gilbert, J, K., \& Watts, D. M. (1983). Concepts, misconceptions and alternative conceptions: changing perspectives in science education. Studies in Science Education, 10, pp.61-98.

Grevatt, A., Gilbert, J. K. \& Newberry, M. (2007). Challenging able science learners through models and modeling, in K. S. Taber, (Ed.), Science Education for Gifted Learners, London: Routledge, pp.85-99.

Griffiths, A. K. \& Preston, K. R (1992). Grade-12 students' misconceptions relating to fundamental characteristics of atoms and molecules. Journal of Research in Science Teaching, 29 (6), pp.611-628.

Hammer, D. (2004). The variability of student reasoning, Lecture 3: Manifold cognitive resources. Proceedings of the Enrico Fermi Summer School in Physics, Course CLVI. Italian Physical Society. Available at http://www.physics.umd.edu/perg/papers/papers-ee.htm

Harrison, A. G. \& Treagust, D. F. (1996) Secondary students' mental models of atoms and molecules: implications for teaching chemistry, Science Education, 80 (5), pp.509-534.

Harrison, A. G. \& Treagust, D. F. (2000). Learning about atoms, molecules, and chemical bonds: a case study of multiple-model use in grade 11 chemistry. Science Education, 84, pp.352-381.

Harrison, A. G. \& Treagust, D. F. (2002). The particulate nature of matter: challenges in understanding the submicroscopic world. In J. K. Gilbert, O. de Jong, R. Justi, D. F. Treagust, \& J. H. van Driel, Chemical Education: Towards Research-based Practice, pp.189-212, Dordecht: Kluwer Academic Publishers.

Hesse, J. J. \& Anderson, C. W. (1992). Students' conceptions of chemical change. Journal of Research in Science Teaching, 29 (3), pp.277-299.

Jenkins, E. W. (2004). From option to compulsion: school science teaching, 1954 2004. School Science Review, $85 \overline{5}(\overline{3} 13), \overline{3} \overline{3}-4 \overline{0}$. 
Johnson, P. M. (1998a). Progression in children's understanding of a 'basic' particle theory: a longitudinal study. International Journal of Science Education, 20 (4), pp.393-412.

Johnson, P. (1998b). Children's understanding of changes of state involving the gas state, part 1: Boiling water and the particle theory. International Journal of Science Education, 20 (5), pp.567-583.

Johnson, P. (1998c). Children's understanding of changes of state involving the gas state, part 2: Evaporation and condensation below boiling point. International Journal of Science Education, 20 (6), pp.695-709.

Johnson, P. (2000a). Children's understanding of substances, part 1: recognising chemical change. International Journal of Science Education, 22 (7), pp.719737.

Johnson, P. (2002b). Children's understanding of substances, part 2: explaining chemical change. International Journal of Science Education, 24_(10), pp.10371054

Johnson. P. M. (2005). The development of children's concept of a substance: A longitudinal study of interaction between curriculum and learning. Research in Science Education, 35(1), pp. 41-61.

Johnstone, A. H. (2000). Teaching of Chemistry - logical or psychological? Chemistry Education: Research and Practice in Europe 1 1(1), 9-15.

Key Stage 3 National Strategy. (2003a) Strengthening teaching and learning of particles in Key Stage 3 science: Main messages. London: Key Stage 3 National Strategy, Department for Education and Skills.

Key Stage 3 National Strategy. (2003b). Strengthening teaching and learning of particles in Key Stage 3 science: Notes for participants. London: Department for Education and Skills.

Kvale, S. (1996) InterViews: An introduction to qualitative research interviewing, Thousand Oaks, California: SAGE Publications.

Leach, J. \& Scott, P. (2002). Designing and evaluating science teaching sequences: an aproach drawing upon the concept of learning demand and a social constructivist perspective on learning. Studies in Science Education, 38, pp.115142.

Lijnse, P. L., Licht, P., de Vos, W., \& Waarlo, A. J. (Eds.). (1990). Relating Macroscopic Phenomena to Microscopic Particles: a central problem in secondary science education. University of Utrecht: CD- $\beta$ Press.

Millar, R. \& Osborne, J. (1998). Beyond 2000: Science education for the future. London: King's College.

MoE (1993). Science in the New Zealand Curriculum. Ministry of Education, Wellington: Learning Media.

NAS (1996) National Science Education Standards. National Research Council of the National Academy of Sciences. Washington DC: National Academy Press.

Needham, R., \& Hill, P. (1987). Teaching strategies for developing understanding in science. Leeds, UK: Centre for Studies in Science and Mathematics Education, Children's Learning in Science Project.

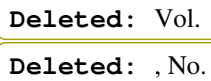


Novick \& Nussbaum (1981). Pupils' understanding of the particulate nature of matter: * a cross age study. Science Education, 65 (2), 187 - 196.

NRC (2002). Scientific Research in Education. National Research Council Committee on Scientific principles for educational research. Washington DC: National Academies Press.

Nussbaum, J. \& Novick, S. (1982). Alternative frameworks, conceptual conflict and accommodation: toward a principled teaching strategy. Instructional Science, 11 , pp. $183-200$.

Osborne, R. J., \& Wittrock, M. (1985). The generative learning model and its implications for science education. Studies in Science Education, 12, $59-87$.

Papageorgiou, G. \& Johnson, P. (2005). Do particle ideas help or hinder pupils' understanding of phenomena? International Journal of Science Education, 27 (11), pp. 1299-1317.

Pope, M. L., \& Denicolo, P. (1986). Intuitive theories - a researcher's dilemma: some

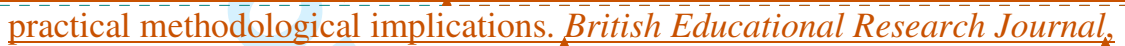
12(2), 153-166.

QCA (2000). Key stage 3 schemes of work. Science Unit 7G: Particle model of solids, liquids and gases. London: Qualifications and Curriculum Authority.

Formatted: references
Formatted: Font: Italic
Deleted:
Formatted: Font: Not Bold
Formatted: Font: Not
Formatted: Font: Not Bold

QCA (2001). Standards at key stage 3 Science: A report for headteachers, heads of department, science teachers and assessment coordinators on the 2000 national curriculum assessments for 14-year-olds. London: Qualifications and Curriculum Authority.

QCA (2003). Standards at key stage 3 Science: A report for headteachers, heads of department, science teachers and assessment coordinators on the 2002 national curriculum assessments for 14-year-olds. London: Qualifications and Curriculum Authority.

QCA (2004). Programme of study: science Key stage 4. London: Qualifications and Curriculum Authority.

QCA (2005). Science: Changes to the curriculum from 2006 for key stage 4. London: Qualifications and Curriculum Authority.

QCA (2007a). Science: Programme of study for Key Stage 3 and attainment targets. London: Qualifications and Curriculum Authority.

QCA (2007b). The new secondary curriculum. What has changed and why? London: Qualifications and Curriculum Authority.

Renström, L., Andersson, B., \& Marton, F. (1990). Students' conceptions of matter. Journal of Educational Psychology, 82 (3), pp.555-569.

Schmidt, H-J. (1991). A label as a hidden persuader: chemists' neutralization concept. International Journal of Science Education, 13 (4), pp.459-471.

SI (1989) The Education (National Curriculum) (Attainment Targets and Programmes of Study in Science) Order 1989. Statutory Instrument 1989 No. 309. London: HMSO. 
Smith, J. P., diSessa, A. A., \& Roschelle, J. (1993). Misconceptions reconceived: a constructivist analysis of knowledge in transition. The Journal of the Learning Sciences, 3(2), 115-163.

Stahly, L. L., Krockover, G. H., \& Shepardson, D. P. (1999). Third grade students' ideas about the Junar phases. Journal of Research in Science Teaching, 36(2), $159-1 \overline{7} \overline{7}$.

Stoll, L., Stobart, G., Martin, S., Freeman, S., Freedman, E., Sammons, P., Smees, R., Jones, S., Maw, N., Cuttance, P. \& Muschamp, Y. (2003). Preparing for

I Change: Evaluation of the Implementation of the Key Stage 3 Strategy Pilot. London: Department for Education and Skills.

I Watts, D. M. \& Gilbert, J. (1983). Enigmas in school science: students' conceptions for scientifically associated words. Research in Science and Technological Education, 1 (2), 1983, pp.161-171.

White, R. \& Gunstone, R. (1992). Probing Understanding. London: The Falmer Press.

Wightman, T., Green, P., \& Scott, P. (1986). The Construction of Meaning and Conceptual Change in Classroom Settings: Case Studies on the Particulate

| Nature of Matter. Leeds: Children's Learning in Science Project, Centre for Studies in Science and Mathematics Education.

Author1 (1985) journal article in School Science Review.

Formatted: Font: Not Bold

Formatted: Font: Not

Formatted: Font: Not Bold

Formatted: Font: Not Bold

Deleted: $G$

Formatted: Font: Not Bold

Deleted: S

Formatted: Font: Not Bold

Deleted: I

Formatted: Font: Not Bold

Deleted: L

Formatted: Font: Not Bold

Deleted: $\mathrm{P}$

Formatted: Font: Not Bold

Formatted: Font: Not

Formatted: Font: Not Bold

Deleted: learning

Deleted: science

Deleted: project

Author1 (2001) journal article in Chemistry Education: Research and Practice in Europe.

Author1 (2002a) book, London: Royal Society of Chemistry.

Author1 (2002b) journal article in British Educational Research Journal.

Author1 (2003) journal article in Foundations of Chemistry.

Author1 (2004) journal article in Science Education.

Author1 (2006) journal article in Studies in Science Education.

Author1 (2007) book, Sage Publications

Author1 (2008) journal article in Science \& Education

Author1 (in press) journal article in International Journal of Science Education.

Author 1 \& colleague (1996) journal article in International Journal of Science Education.

Colleague and Author1 (2005) book, London: Routledge.

Colleague \& Author1 (2007) Chapter in international handbook.

Colleague \& Author1 (in press) International Journal of Science Education

Deleted: under review) journal Author2 (2005) Seminar paper, available through education-line 
"In Year 7, early work on particles should introduce pupils to: a simple model of matter made up of particles; how that model can be used to explain physical phenomena such as diffusion and gas pressure, and changes of state such as melting and solidifying...

Once these aspects have been established challenge pupils to apply their developing understanding of particles to explain other physical phenomena, such as expansion. As they meet a wider range of physical and chemical phenomena, they should develop a more sophisticated view of atoms as fundamental building blocks of matter, and use this new understanding...

At the same time, teach them to recognise the limitations of the simple model of matter...

Pupils will use particles to explain a wide range of physical, biological and geological phenomena, such as the movement of substances through cell membranes, photosynthesis, digestion, and the formation of crystals in rocks. They will also consider how energy is transferred by the movement of particles in conduction, convection and evaporation."
Deleted: Figure 1: The framework for teaching all lower secondary pupils to use particle ideas $I$

Formatted: legend, Automatically adjust right indent when grid is defined, Widow/Orphan control, Adjust space between Latin and Asian text, Adjust space between Asian text and 
Year 7

pupils

should

be taught

to:

Figure 2: Teaching objectives for the three years of lower secondary science (from DfES, 2002: 28)

Formatted: table

contents, Automatically

adjust right indent when grid is defined,

Widow/Orphan control, Adjust space between

Latin and Asian text,

Formatted Table
Formatted: table

contents, Automatically

adjust right indent when

grid is defined,

Widow/Orphan control,

Adjust space between

Latin and Asian text,

Adjust space between
Formatted: table

contents, Automatically adjust right indent when grid is defined, Widow/Orphan control, Adjust space between Latin and Asian text, Adirct enaen hetween 
Figure 3: Classification of interview episodes by use of particle

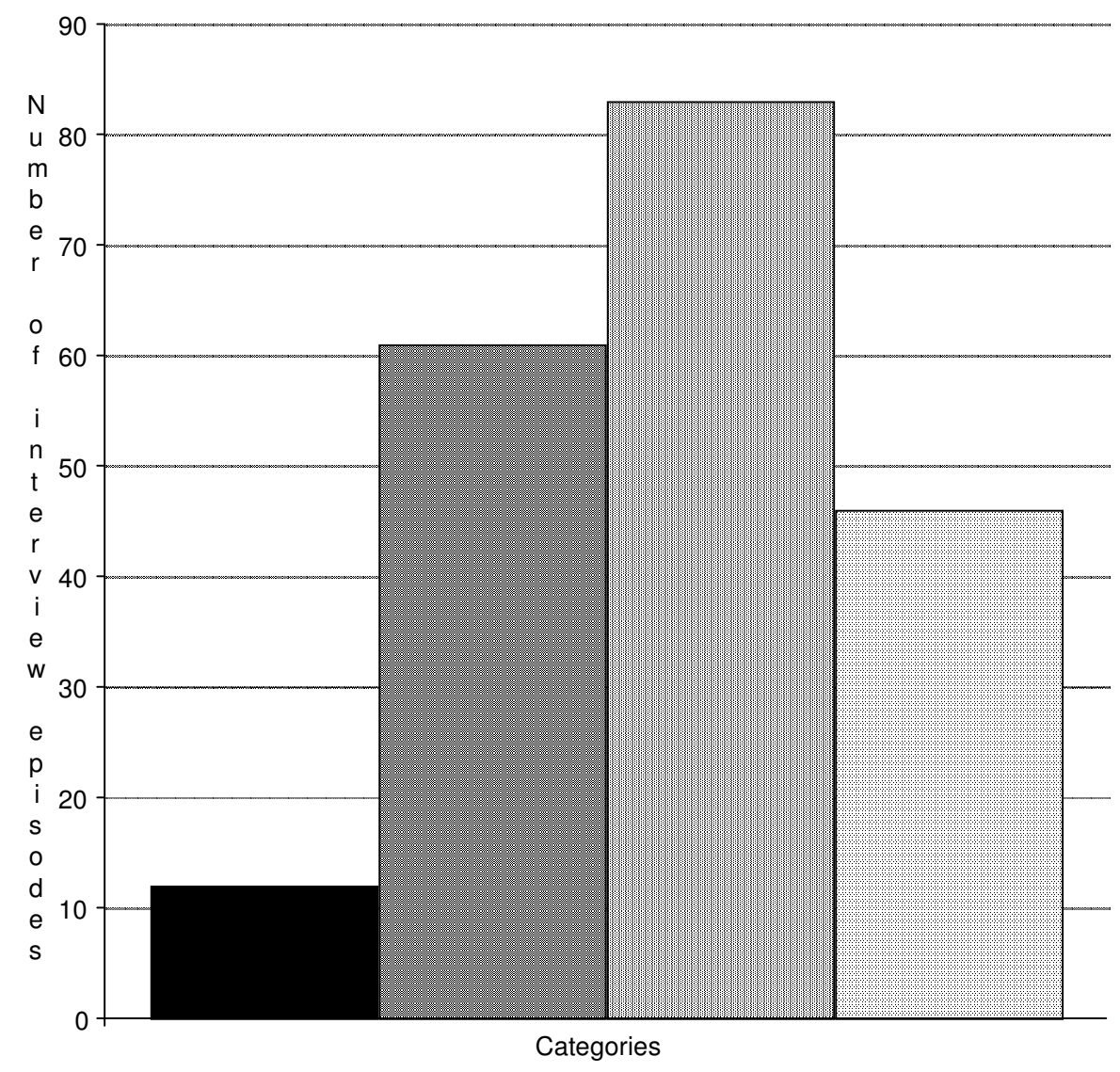

$\mathrm{N}$ - no explanation

$\square \mathrm{M}$ - explanations using macroscopic ideas only

D. 1 1 - explanations using 'alternative' particle ideas

P2 - explanations using particles ideas matching target knowledge

Deleted: Figure 2:

Classification of interview episodes

by use of particle ideas in student explanations

Formatted: Left 


\begin{tabular}{|c|c|c|c|c|c|}
\hline school & Y7 & Y8 & Y9 & Y10 & Y11 \\
\hline 1 & 3 & 4 & 3 & 3 & 4 \\
\hline 2 & - & - & 2 & 3 & - \\
\hline 3 & - & 4 & 8 & 2 & - \\
\hline 4 & - & - & 1 & 2 & - \\
\hline 5 & - & - & 4 & 3 & 4 \\
\hline total & 3 & 8 & 18 & 13 & \\
\hline
\end{tabular}

Table 1: The spread of students interviewed across schools and year groups 


\begin{tabular}{|c|c|c|c|c|c|}
\hline year & $\begin{array}{c}\text { No of } \\
\text { episodes in } \\
\text { database }\end{array}$ & $\mathrm{N}$ & $\mathrm{M}$ & $\mathrm{P} 1$ & $\mathrm{P} 2$ \\
\hline $7(\mathrm{KS} 3)$ & 8 & 1 & 3 & 4 & - \\
\hline $8(\mathrm{KS} 3)$ & 13 & 1 & 5 & 4 & 3 \\
\hline $9(\mathrm{KS} 3)$ & 28 & 2 & 3 & 17 & 6 \\
\hline $10(\mathrm{KS} 4)$ & 24 & 2 & 11 & 8 & 3 \\
\hline $11(\mathrm{KS} 4)$ & 6 & 1 & - & 3 & 2 \\
\hline total & $\mathbf{7 9}$ & $\mathbf{7}$ & $\mathbf{2 2}$ & $\mathbf{3 6}$ & $\mathbf{1 4}$ \\
\hline
\end{tabular}

Table 2: Classification of students' explanations of dissolving 


\begin{tabular}{|c|c|c|c|c|c|}
\hline year & $\begin{array}{c}\text { No of } \\
\text { episodes in } \\
\text { database }\end{array}$ & $\mathrm{N}$ & $\mathrm{M}$ & $\mathrm{P} 1$ & $\mathrm{P} 2$ \\
\hline $7(\mathrm{KS} 3)$ & 2 & - & 1 & 1 & - \\
\hline $8(\mathrm{KS} 3)$ & 2 & 1 & - & 2 & - \\
\hline $9(\mathrm{KS} 3)$ & 13 & 1 & 1 & 5 & 9 \\
\hline $10(\mathrm{KS} 4)$ & 11 & - & - & 2 & 11 \\
\hline $11(\mathrm{KS} 4)$ & 13 & $\mathbf{2}$ & $\mathbf{5}$ & $\mathbf{1 0}$ & $\mathbf{2 4}$ \\
\hline total & $\mathbf{4 1}$ & & & & 4 \\
\hline
\end{tabular}

Table 3: Classification of students' explanations of physical changes 


\begin{tabular}{|c|c|c|c|c|c|}
\hline year & $\begin{array}{c}\text { No of } \\
\text { episodes in } \\
\text { database }\end{array}$ & $\mathrm{N}$ & $\mathrm{M}$ & $\mathrm{P} 1$ & $\mathrm{P} 2$ \\
\hline $7(\mathrm{KS} 3)$ & 2 & - & 2 & - & - \\
\hline $8(\mathrm{KS} 3)$ & 3 & 1 & 2 & - & - \\
\hline $9(\mathrm{KS} 3)$ & 9 & - & 2 & 7 & - \\
\hline $10(\mathrm{KS} 4)$ & 13 & - & 6 & 6 & 1 \\
\hline $11(\mathrm{KS} 4)$ & 5 & - & 1 & 2 & 2 \\
\hline total & $\mathbf{3 2}$ & $\mathbf{1}$ & $\mathbf{1 3}$ & $\mathbf{1 5}$ & $\mathbf{3}$ \\
\hline
\end{tabular}

Table 4: Classification of students' explanations of mixing 


\begin{tabular}{|c|c|c|c|c|c|}
\hline year & $\begin{array}{c}\text { No of } \\
\text { episodes in } \\
\text { database }\end{array}$ & $\mathrm{N}$ & $\mathrm{M}$ & $\mathrm{P} 1$ & $\mathrm{P} 2$ \\
\hline $7(\mathrm{KS} 3)$ & 2 & - & 1 & 1 & - \\
\hline $8(\mathrm{KS} 3)$ & 6 & - & 1 & 3 & 2 \\
\hline $9(\mathrm{KS} 3)$ & 11 & - & 4 & 6 & 1 \\
\hline $10(\mathrm{KS} 4)$ & 7 & - & 2 & 4 & - \\
\hline $11(\mathrm{KS} 4)$ & - & - & - & $\mathbf{1 4}$ & $\mathbf{4}$ \\
\hline total & $\mathbf{2 6}$ & $\mathbf{0}$ & $\mathbf{8}$ & & 1 \\
\hline
\end{tabular}

Table 5: Classification of students' explanations of chemical reactions 


\begin{tabular}{|c|c|c|c|c|c|}
\hline year & $\begin{array}{c}\text { No of } \\
\text { episodes in } \\
\text { database }\end{array}$ & $\mathrm{N}$ & $\mathrm{M}$ & $\mathrm{P} 1$ & $\mathrm{P} 2$ \\
\hline $7(\mathrm{KS} 3)$ & 1 & - & 1 & - & - \\
\hline $8(\mathrm{KS} 3)$ & 2 & - & - & 2 & - \\
\hline $9(\mathrm{KS} 3)$ & 13 & 2 & 7 & 4 & - \\
\hline $10(\mathrm{KS} 4)$ & 5 & - & 5 & - & - \\
\hline $11(\mathrm{KS} 4)$ & 3 & - & - & 2 & 1 \\
\hline total & $\mathbf{2 4}$ & $\mathbf{2}$ & $\mathbf{1 3}$ & $\mathbf{8}$ & $\mathbf{1}$ \\
\hline
\end{tabular}

Table 6: Classification of students' explanations of non-mixing 


\begin{tabular}{|c|c|c|c|c|c|}
\hline $\begin{array}{l}\text { Class of } \\
\text { Phenomena }\end{array}$ & $\begin{array}{l}\text { No of } \\
\text { episodes in } \\
\text { database }\end{array}$ & $\mathrm{N}$ & M & $\mathrm{P} 1$ & $\mathrm{P} 2$ \\
\hline Dissolving & 79 & 7 & 22 & 36 & 14 \\
\hline $\begin{array}{l}\text { Physical } \\
\text { changes }\end{array}$ & 41 & 2 & 5 & 10 & 24 \\
\hline Mixing & 32 & 1 & 13 & 15 & 3 \\
\hline $\begin{array}{l}\text { Chemical } \\
\text { reactions }\end{array}$ & 26 & - & 8 & 14 & 4 \\
\hline Immiscibility & 24 & 2 & 13 & 8 & 1 \\
\hline Overall & 202 & $12(6 \%)$ & $61(30 \%)$ & $83(41 \%)$ & $46(23 \%)$ \\
\hline
\end{tabular}

Table 7: The overall classification of interview episodes 


\begin{tabular}{|c|c|c|c|c|c|}
\hline year group & $\begin{array}{c}\text { No of } \\
\text { episodes in } \\
\text { database }\end{array}$ & N & M & P1 \\
\hline $7(\mathrm{KS} 3)$ & 15 & 1 & 8 & 6 & - \\
\hline $8(\mathrm{KS} 3)$ & 26 & 2 & 8 & 11 & 5 \\
\hline $9(\mathrm{KS} 3)$ & 74 & 5 & 19 & 39 & 11 \\
\hline $10(\mathrm{KS} 4)$ & 60 & 3 & 25 & 18 & 16 \\
\hline $11(\mathrm{KS} 4)$ & 27 & 1 & 1 & 9 & $\mathbf{4 6}$ \\
\hline total & $\mathbf{2 0 2}$ & $\mathbf{1 2}$ & $\mathbf{6 1}$ & $\mathbf{8 3}$ & Formatted: English U.S. \\
\hline
\end{tabular}


Notes:

\begin{abstract}
${ }^{\mathrm{i}}$ Although the UK is considered one nation with a national government, there are variations in the education systems in the different constituent countries. In particular, Scotland has a completely different curriculum to the rest of the UK. This paper refers to the English context, and the 'national' curriculum and 'national' tests here signify England.

${ }^{\text {ii }}$ Under the ENC, students in state schools are expected to study mathematics, English and science through the 11 years of compulsory schooling. The majority of upper secondary students follow a science course that is certified as equivalent to two subjects on leaving school ('double science'). There is the provision for students of low achievement (or those with strong linguistic skills who wish to study several foreign languages) to follow a more restricted science curriculum during the final two years of compulsory schooling ('single science'). Some students take biology, chemistry and physics as separate examinations subjects ('triple science'), where examination specifications also include additional topics not part of the mandated curriculum.
\end{abstract}




\title{
Secondary students' thinking about familiar phenomena: learners' explanations from a curriculum context where 'particles' is a key idea for organising teaching and learning.
}

\author{
Abstract: \\ Particle models of matter are widely recognised as being of fundamental importance \\ in many branches of modern science, and particle ideas are commonly introduced and \\ developed in the secondary school curriculum. However, research undertaken in a \\ range of national contexts has identified significant learning difficulties in this topic, \\ and suggests that notions of particles that match scientific models are generally only \\ attained over periods of some years. A National Curriculum in Science was imposed \\ in England over the period 1989-1993, followed by increasingly prescriptive guidance \\ to teachers. This culminated in a framework for teaching lower secondary science, \\ which identified 'particles' as one of five key ideas for organising teaching and \\ learning of science to all 11-14 year olds. In this curriculum context, a basic particle \\ model is introduced at the start of secondary education, and consolidated by being \\ revisited in various contexts over three years. However National Tests suggest that \\ only a minority of pupils attain levels of understanding matching target knowledge \\ during this phase of schooling. The present paper reports an interview-about-events \\ based study that explored how a sample of English secondary students explained \\ phenomena commonly met in school science. It was found that students generally \\ Deleted: the way \\ used the notion of particles in their responses, although most of their particle-based \\ explanations reflected alternative conceptions that have been reported in previous \\ research. It is concluded that a curriculum strategy of early introduction and regular \\ application during the early secondary years is not of itself sufficient to support the \\ desired progression in thinking with particle concepts, and more sophisticated \\ Deleted: level of \\ research-informed pedagogy is needed.




\section{Secondary students' thinking about familiar phenomena: student explanations in a curriculum context where 'particles' is a key idea for organising teaching and learning.}

\section{Introduction}

This paper presents findings from an interview study that explored secondary level

Deleted: considers students' explanations of basic phenomena commonly met in school chemistry. The study was carried out in a curriculum context where the notion of 'particles' is

explicitly recommended as one of the 'key ideas' around which science teaching

Deleted: considered should be structured. Previous research (discussed below) has highlighted the difficulties that many students have in acquiring an understanding of the models used by scientists to describe matter at submicroscopic level. The importance of this topic in science is widely acknowledged, as are some of the reasons why it provides a challenge to school age learners (Lijnse, Licht, de Vos, \& Waarlo, 1990; Author1, 2001; Harrison \& Treagust, 2002).

In recent years the UK government has funded an extensive initiative to develop pedagogic strategies and support teaching of the English National Curriculum (ENC) ${ }_{-}^{\text {i }}$ In science, this guidance and associated professional development support, has been organised around five 'key ideas', one of which is 'particles'. This new curriculum context provided the background for the study reported here, which explored the way

Deleted: $\mathrm{n}$
Deleted: science c
Deleted: $\mathrm{T}$
Deleted:,
Deleted: supplemented by
students explained basic phenomena that school science would model in terms of the interactions and properties of particles such as molecules and ions. In particular, we have analysed student explanations offered in interviews to investigate whether the explicit status of 'particles' as a key idea, and the investment in teacher support designed to 'strengthen teaching and learning of particles' (KS3NS, 2003a, 2003b) has facilitated teaching that has overcome the well-reported learning difficulties in this topic.

The outcomes of National Testing exercises for 14 year-olds in England, which assign students to 'levels' of attainment (as discussed below) suggest that although 'particles' is recommended as a central concept in teaching lower secondary schools 
science, only a minority of pupils are likely to have developed an understanding of basic particle ideas by the end of this phase of schooling. In this paper we briefly describe the centrality of the particle concept in the current English secondary science curriculum, and explain the potential significance of the National Testing outcomes, as a context for reporting the results of an analysis of our interviews in terms of the extent to which students drew upon 'target knowledge' when explaining basic phenomena such as dissolving. Our informants commonly used a notion of particles in their explanations, although generally not in ways consistent with the teaching models. As the English context is one where considerable official guidance and support has been provided to 'strengthen' teaching and learning about particles (KS3NS, 2003a, 2003b), we consider our findings are potentially significant for all educational systems where secondary level students are taught particle models of matter.

\section{The centrality of particle models in science}

Particle ideas are central to modern science. Indeed Richard Feynman suggested that if only one idea from science was to survive some future cataclysm, then the notion that everything is made of tiny particles, with inherent motion, that attracted or repelled each other depending upon separation, would be his candidate for the most useful starting point for rebuilding (reported in Feynman, Leighton \& Sands, 1963: 12). As Feynman pointed out, a great deal can be deduced and understood from that hypothesis. Increasingly detailed refinements of this basic idea are central to many branches of modern science.

The centrality of particle models in science has led to particle ideas being given high prominence in the science curriculum in many countries (e.g. MoE, 1993; NAS, 1996; DfEE/QCA, 1999). Within Chemistry, the concept is fundamental to any kind of advanced study (e.g. Ault, Novak and Gowin, 1984).

\section{Students' difficulties in learning about particles}

It is well established that students find these ideas difficult to learn (e.g. Renström, Andersson \& Marton, 1990; Nussbaum \& Novick, 1982; Ault, Novak \& Gowin, 1984; Ben-Zvi, Eylon \& Silberstein, 1986; Briggs \& Holding, 1986; Wightman,

Deleted: The study is not based upon a representative sample of English secondary pupils, but we note that these findings are consistent with the outcomes of official National Testing of all pupils at age 14 .

Deleted: we might imagine this offers something of a 'best-case' scenario, and so 
Green \& Scott, 1986; Griffiths \& Preston, 1992; Harrison \& Treagust, 2002; Author1, 2003). Hesse \& Anderson (1992: 277) reported from their study of high schools students who had completed a unit of study on chemical change that, despite the emphasis on particle ideas in their course, most of the students failed "to invoke atoms and molecules as explanatory constructs".

For many secondary age learners, the particle models of matter presented in the curriculum offer a considerable learning demand, i.e. the extent to which target knowledge differs from a student's current understanding (Leach and Scott, 2002). These 'particles' - molecules, ions, atoms etc. - have properties quite unlike the particles (i.e. grains, specks) of students' everyday experience. Indeed the use of a familiar term may ultimately be unhelpful (cf. Watts \& Gilbert, 1983; Schmidt, 1991), and it has been suggested that an alternative such as 'quanticles' might be advisable (Author1, 2005).

Some studies show quite fundamental misunderstandings of the scientific models represented in the science curriculum (Author1, 2001). For example, when first learning about particles, it is not unusual for learners to conceptualise particles embedded within materials (rather than materials composed only of the particles), or to assume that air flows between the particles (Nussbaum \& Novick, 1982; Ault, Novak \& Gowin, 1984; Renström, Andersson \& Marton, 1990; Griffiths and Preston, 1992; Wightman, Green \& Scott, 1986: 195).

Learners may also fail to appreciate how the fundamental particles of a substance can be identical (Griffiths \& Preston, 1992), and unchanged during a change of state (Ben-Zvi, Eylon \& Silberstein, 1986; Ault, Novak \& Gowin, 1984; Wightman et al., 1986: 276; Griffiths \& Preston 1992). The notion of particles having inherent unceasing motion also proves difficult for learners (Nussbaum \& Novick, 1982; Wightman et al, 1986).

Where scientists explain the properties of materials in terms of the conjectured (different) properties of the component particles, students will often simply assign the macroscopic property to the particle, and then use this as an explanation (Renström, Andersson \& Marton, 1990; Griffiths \& Preston, 1992; Briggs \& Holding, 1986), e.g. solids are hard because they are made up from hard particles. Ben-Zvi, Eylon and 
Silberstein (1986) found that nearly half (c.46\%) of a sample of 300 Israeli high school students (aged about 15 years) ascribed inappropriate properties of a material to its individual atoms: properties such as electrical conduction, malleability, colour, odour and reactivity. It is also common for students' explanations in terms of particles to be teleological or anthropomorphic, e.g. the particles 'want' to move away from each other (Driver, 1983; Wightman et al, 1986; Griffiths \& Preston, 1992; Author1 \& Colleague, 1996).

\section{Progression in understanding particle models}

Just as lower secondary level students experience problems making sense of the basic particle theory introduced in school science, more advanced high school students commonly have difficulty acquiring the more complex particle models involving atoms, molecules, ions, electrons, etc. that are presented at upper secondary (high school) level (Author1, 2001) - something that should not be surprising as the basic model provides the foundations for the more advanced models.

Similarly, the yet more nuanced and sophisticated models introduced in college level studies, which build in turn on the learning prescribed (but not always achieved) in upper secondary school, lead to further difficulties for the group of students interested and successful enough to opt for further science studies (Harrison \& Treagust, 2000; Author1, 2005; Colleague \& Author1, 2007).

\section{Developing understanding of particle ideas}

Renström, Andersson and Marton interviewed 20 Swedish pupils in grades 7-9 (i.e. 13 - 16 years of age) about their "understanding of one of the most central questions in chemistry: the nature of matter" (1990, p.555). In their interview study Renström and coworkers used nine common materials as foci for discussion: salt, iron, aluminum, wood, water, oil, air, oxygen and carbon dioxide. They had a prepared script of questions, but also followed up the range of responses on an individual basis. The analysis of interview protocols followed what they called "a nonalgorithmic, interpretative 'discovery procedure'..." (Renström et al., 1990, p.557) leading to a description of possible ways of thinking about matter.

Six distinct 'conceptions of matter' were identified, although "the same student can very well adopt different conceptions as a background for reasoning about different problems and different substances" (p.558). The six conceptions were: 
(a) a homogeneous substance - the substance is not delimited from other substances and it lacks substance attributes.

(b) the substance is delimited from other substances and it exists in more than one form (which creates the potential for thinking of phase transition).

(c) substance units with small particles that may be different from the substance in which they are embedded (which creates the potential for thinking of atoms, which are components of the substance but do not have its macroproperties).

(d) aggregates of particles - the substance consists of infinitely divisible particles, which might not consist of the substance.

(e) particle units - the substance consists of particles that are not divisible into other particles and that have certain attributes (such as form and structure) that may explain macroproperties of the substance.

(f) systems of particles - the substance consists of systems of particles. Different macroproperties of the substance can be accounted for in terms of particles and particle systems.

Renström et al., 1990: 558, 560, 565-566.

Renström et al considered these six conceptions to form a hierarchy (p.558) in terms of increasing explanatory power and more detailed understanding, so that at the higher levels of the scheme the increasing sophistication of the conceptions begins to approach the notion of matter presented in school science as target knowledge.

Renström et al reported that even those learners operating at the most inclusive level of the hierarchy (that "closest to that aimed at in chemistry teaching" where "matter was conceptualized in terms of particle (or subparticle) systems and the relations between particles", pp.563-564) did not demonstrate a conception of matter which could explain all that was expected by age 16 . So even the most sophisticated conception uncovered was not a 'final stage' in terms of the intended target knowledge.

Although learning pathways should not be inferred from cross-sectional studies (as longitudinal research is needed to follow the actual trajectories learners' ideas take), the Renström et al. study suggests that the acquisition of particle ideas that match curriculum models may involve a considerable gestation. 
In the UK, where the study reported here was undertaken, analysis of data from National Surveys carried out in the 1980s by the government's Assessment of Performance Unit (e.g. APU 1989a) identified common misunderstandings of basic chemical ideas, including the application of basic particle models (Brook, Briggs \& Driver, 1984; Briggs \& Holding, 1986). Classroom-based case studies (Wightman et al, 1986) again found students having difficulty acquiring scientific meanings for particle ideas.

Johnson (1998a, b, c, 2000a, b, 2005) undertook a detailed study of a group of students learning about basic chemical ideas in lower secondary science during the period 1990-1993. This coincided with the introduction of the ENC (Educational Reform Act, 1988; SI, 1989). Johnson's school science staff revised their lower school teaching scheme to meet the new curriculum requirements This scheme was piloted with the new intake in September 1989, and the following year's intake included the class Johnson investigated for his study (Johnson, P. M., personal communication, $26^{\text {th }}$ October, 2007).

Johnson drew upon the Renström et al. model discussed above, and developed an analytical scheme for a 'basic' particle model suitable for the lower secondary years in relation to the teaching scheme being used in the study school (Johnson, 1998a). The basic particle model did not distinguish between molecules, ions, etc., and did not consider internal structure. There were four main stages in the analytical scheme Johnson adopted: where particle ideas were not used by students: where they referred to particles but considered them embedded in a substance; where they accepted the particles were the substance, but assigned them macroscopic properties; and where particles with one set of properties made up the substance and collectively gave it distinct macroscopic properties.

Johnson (1998a) suggested that his findings could be seen in an optimistic light. Over the three years of lower school science there was evidence that most pupils made progress towards the target knowledge. This suggested that the particle ideas that did not match curriculum models were none-the-less acting as suitable intermediate conceptions on a conceptual trajectory towards understanding matching target knowledge (cf. Driver, 1989; Driver, Leach, Scott \& Wood-Robinson, 1994). particles in the English context $\mathbb{I}$ The research findings discussed above derive from an international literature.

Deleted: These studies were undertaken before a National Curriculum was introduced in England (henceforth ENC) that mandated the science to be taught during the compulsory school years (ages 5-16), and which provides the curriculum context for the study we report below.

Deleted: (schools had previously had total freedom to select science content to teach, as discussed below.) 
Despite his optimism, Johnson's results also showed that even in a teaching context carefully planned to support progression in this topic area, the acquisition of the desired level of understanding was developed slowly,

\begin{abstract}
Although many pupils remained in the same category for a pair of consecutive interviews, over the longer time span the evidence is that most of the pupils did change in their thinking, and with a considerable number moving to [the final] model.
\end{abstract}

Johnson, 1998a: 402

A little under half of the group had reached this 'particles are the substance, properties of state are collective' level in his final round of interviews (Johnson, 1998a: 402). Johnson suggested that intrinsic motion was a difficult idea for students to master, although they could progress to the final stage of his basic particle model without appreciating this. He also recommended that more emphasis should be placed on inter-particle attractions when teaching a basic particle model (see also Papageorgiou \& Johnson, 2005). Whilst acknowledging that generalization from a single school is unwise, Johnson recommended that,

it seems prudent to assume that it will take time for pupils to come to terms with the basic particle model. This might mean that the introduction of further ideas will need to be delayed.

Johnson, 1998: 410

Such 'further' ideas might include the distinction between different types of submicroscopic particles making up different materials (molecules, ions, etc.); the structure of atoms; the bonding and structure in different types of materials (salt, metal, sugar, water, etc).

\title{
Particle ideas in the English National Curriculum
}

The centrality of particle ideas in science is reflected in the English school curriculum. The study reported below was undertaken in state schools in England, where the curriculum context is the ENC, a statutory document published by the government education ministry and its agency for overseeing curriculum and national qualifications (DfEE/QCA, 1999). Whilst it was common for particle ideas to be taught in secondary science lessons in England prior to the introduction of the ENC, 
- a basic model of atomic structure (KS4-Sc3-1a-d);

- how this sub-atomic level of structure is used to explain the properties of different substances (KS4-Sc3-1g-k);

- how chemical change depends upon particle interactions (KS4-Sc3-1f);

- how reactivity depends upon atomic structure (KS4-Sc3-1e);

- how particle theory can be used to explain reaction rates (KS4-Sc3-3p);

- how atomic structure is the basis for systemizing a study of the chemical elements (KS4-Sc3-3b-c);

- particle models to explain nuclear radiation (KS4-Sc4-6a, c);

- particle models of electrical current (KS4-Sc4-1m, p).

Deleted: Prior to the introduction of the ENC, schools had the responsibility of deciding which material to teach, in what sequence, and to which age groups. Jenkins (2004: 36) describes how English school science teachers had "a remarkable degree of freedom over their own work". Although schools were in practice constrained by the need to prepare students for school leaving examinations (taken at age 16), this was a limited constraint. There was no requirement for all students to take sciences as examination subjects, and where they did the schools had flexibility in selecting from (or even developing) a wide range of syllabuses to meet the interests and attainment levels of different groups of students. So some students took examinations in biology, chemistry and physics; but others selected one (or in some

schools none) of these subjects, or might select more practical alternatives (e.g. automotive engineering science, rural science, etc.), II

"In many ways, science teachers in the 1960 s and 1970 s were working within an educational free market. They were free, at least in principle, to choose from a range of syllabuse or, subject to constraints, construct their own courses and examine their own pupils for public certification.' $I$ Jenkins, 2004: 37I

This situation changed dramatically with the introduction of the ENC (DES/WO (1988; SI, 1989).

Deleted: year

Deleted: Undoubtedly many students in English schools were taught about particle theory prior to the ENC implementation, but with the new curriculum came the requirement that all schools must teach these ideas to all their students across the ability range in the lower secondary school. II 


\section{A key idea in the science teaching Framework}

The ENC set out prescribed content that schools were required to teach, but individual schools maintained the responsibility for organising teaching and sequencing content. However, after a decade of English schools working with a prescribed curriculum, a revision of the ENC published in 1999 (DfEE/QCA, 1999) was followed by a series of major initiatives funded by the UK government intended to raise pupil attainment by offering schools guidance on how to implement the curriculum.

The government funded Qualifications and Curriculum Authority (QCA) published a model scheme of work, suggesting how teachers might sequence topics and approach teaching. Whilst the model scheme, covering the first three years of secondary education, was not compulsory, it became the expectation (for example among school Inspectors) that schools would either use the QCA model as the starting point for their own schemes, or be able to justify taking a different approach. Once the officially sanctioned scheme was published, it also became a reference point for commercial publishers, so that textbooks intended for this age group were written to fit the $\underline{\text { scheme. }}$

For example, the unit introducing particle theory ('Particle model of solids, liquids and gases'), is intended to be taught in the first year of secondary school, and to act as the basis for later teaching and learning about particles,

This unit lays the foundation for subsequent work on particles. Pupils will have many opportunities in later units to try to explain phenomena in terms of particles, e.g. dissolving in unit $7 \mathrm{H}$ 'Solutions', changes of state in unit 8I 'Heating and cooling', digestion in unit $8 \mathrm{~A}$ 'Food and digestion', crystal size related to rate of cooling in unit $8 \mathrm{H}$ 'The rock cycle', the behaviour of gases in unit 9L 'Pressure and moments'.

QCA, 2000: 1

A 'National Strategy' (initially called the 'Key Stage 3 Strategy', later re-branded the 'Secondary Strategy', and henceforth referred to as 'the Strategy') was introduced to offer teachers guidance on teaching the ENC. This included a specific science strand, which was developed from the QCA scheme, and made the default assumption that schools were organising teaching according to this model This strand, was piloted in Deleted: the school year 2001-2, and then 'rolled-out' nationally (Stoll et al, 2003). The output 
has included a good deal of guidance issued to teachers, organised around a published 'Framework for teaching science' (DfES, 2002, henceforth 'the Framework') in the three years of the lower secondary key stage, (signified as years 7,8 , and 9 of the 11 years of compulsory schooling).

Whilst officially only a guidance document, the Framework - which like the rest of the science strand was designed around the 'model' QCA Scheme of work - became the referent for a multitude of teacher development opportunities, guidance documents on aspects of pedagogy, and sample teaching resources issued to schools through the Strategy, The Framework, and other Strategy materials and approaches were promoted through a national programme of teacher development courses (that all schools were given funding to access), which were in turn supported ('delivered') by Strategy advisory teachers appointed in each area of the country.

Deleted: Deleted: and Deleted: was Deleted: the appointment of science, to act as foci for teaching the subject. This could be seen as a response to common criticisms of the science curriculum as comprising too many topics (the recommended scheme of work for KS3 organises the curriculum into 37 discrete topics, see Colleague and Author1, 2005), which need to be passed over quickly rather than studied in depth (e.g. Millar \& Osborne, 1998). According to this recommended Framework:

The five key scientific ideas that underpin the Key Stage 3 programme of study are: cells, interdependence, particles, forces [and] energy. It is important to introduce all five key scientific ideas early in Key Stage 3. Pupils need to develop their understanding steadily so that they can recognise, use and then apply each of the ideas in different contexts.

DfES, 2002, p.14

The precise selection of 'key ideas' is open to criticism (Colleague \& Author1, 2005;

Grevatt, Gilbert \& Newberry, 2007), but the presence of '_particles' on any such list would seem essential (Author1, 2002a). The approach recommended in the Framework is based on sensible pedagogic principles, i.e. that the key ideas are introduced early in secondary education, and immediately used in some explanations,

Deleted: Various examples are presented (DfES, 2002:14, 17, 18) to show where particle ideas may be applied "once each idea has been introduced in Year 7" (p.14). II then subsequently being applied widely in a range of contexts to provide further consolidation and reinforcement throughout the three years. Various examples are presented (DfES, 2002: 14, 17, 18) to show where particle ideas may be applied "once 
each idea has been introduced in Year 7"' (p.14), and the Framework offers teachers specific suggestions of where particle ideas should be revisited throughout the three years (DfES, 2002: 28).

The Framework clearly sets out 'particles' as a key idea that should be met and applied by all students in lower secondary science, and where progression from simple to more sophisticated models is expected as the norm within lower secondary science (see Figure 1).

Figure 1: The Framework for teaching all lower secondary pupils to use particle ideas

Teacher professional development materials issued as part of the Strategy, and intended to be used in all schools, spell out the degree of progression expected during lower school science,

Particles is a key scientific idea which is explicitly taught for the first time at Key Stage 3 and permeates science at this age range and thereafter...When teaching about atoms, elements, molecules and compounds in Year 8 it is helpful to use a variety of visual and physical models to develop pupils' understanding...Teaching and learning in Year 9 about conservation of mass and how particles can rearrange is central to developing pupils' understanding of chemical reactions and equations.

DfES, 2003

The Framework set out specific teaching objectives for the 'key ideas' in each of the years of lower secondary science (DfES, 2002). The teaching objectives relating to particles are shown in Figure 2. (The Figure omits objectives relating to the reactions and reactivity of metals included under 'particles' in the Framework that do not explicitly refer to particle models.) Strategy materials for teacher development sessions included a strong focus on some of the common ways students tend to misapply particle ideas, so that one intended outcome of professional development was that "participants should know some of the misconceptions about materials held by many pupils early in Key Stage 3 and be able to suggest a way to counter these" (Key Stage 3 National Strategy, 2003b: 20). However limited reference was made to research findings relating to the origins of learners' difficulties or the evolution of their thinking. 
Figure 2: Teaching objectives for the three years of lower secondary science (from DfES, 2002: 28)

Indications from the National Testing regime

Alongside the introduction of the ENC, a National Testing regime for all pupils was instigated. Reporting on student attainment at age 14 (at the end of the lower secondary 'key stage', KS3) is based around the assignment of students to 'levels' of attainment. Although the reported Test statistics only offer an overall view of student performance, reports produced for teachers offer some more specific indications of areas of weakness, e.g.,

"The application of particle theory to pressure in liquids and gases is not well understood. ... pupils were unable to explain what happens to the spacing between particles when liquids and gases are put under pressure. In 1999, pupils had similar difficulties in explaining how air particles in a tyre exert a pressure"

$$
\text { QCA, 2001: } 11
$$

"Imost pupils] could draw the arrangement of particles in a gas, but only a few recognised that when water vapour is condensed into water the gas molecules which are well separated come into loose contact with one another...pupils had to say what would happen to samples of copper sulphate solution left in an open and in a covered dish. Many pupils did not recognise that evaporation would be faster from the open dish because freely circulating air would allow the vapour particles to diffuse away easily.".

QCA, 2003: 29-30

Such comments seem consistent with level descriptors (which refer to the full range of curriculum topics, not just particles) published in the curriculum documents, which suggest that the ability to apply particle ideas relates to attainment expected only at the higher levels. So at level 6 (which would be considered a high level of attainment at KS3), students will "recognise that matter is made up of particles, and describe differences between the arrangement and movement of particles in solids, liquids and gases". At level 7 they will typically,
Deleted: It is within this curriculum context that the study reported here was undertaken. The present research was timely, as a new programme of study for science within the ENC at KS4 (upper secondary level) was introduced in 2006, and a revised KS3 (lower secondary) curriculum is being introduced in 2008 (see the

Discussion). In both cases the revisions amount to substantive redesigns, rather than peripheral modifications to the previous curriculum requirements. II Over a period of one-and-a-half decades, a highly specified science curriculum has been introduced, reinforced by National Tests, and then supplemented - first by an official model teaching scheme, and then by a detailed 'Framework' for planning and organising science teaching, supported by an extensive Strategy meant to inform pedagogy. Our study coincides with the endpoint of this process of what (in the English context) amounts to an unprecedented attempt to regulate the teaching of science. 
Only at level 8 are students expected to be able to "use the particle model in a wide range of contexts". So-called 'exceptional performance' beyond level 8 is typified by students who "use particle theory in a wider range of contexts, recognising that differences in the properties of materials relate to the nature of the particles within them" and who "understand how the particle model can be used in explaining physical phenomena such as how sweating causes cooling" (DfES/QCA, 1999). According to government statistics (DfES, 2006), National Testing in 2006 showed that $26 \%$ of students were assigned Level 6 and $15 \%$ attained level 7 (the highest level reported for this age group). The percentage of students attaining level 6 or above had not exceeded $40 \%$ in any of the previous 11 years of National Testing. $\underline{\text { So by the end of KS3, about three-fifths of students are at level } 5 \text { or below. To the }}$ extent that levels assigned in National Tests can be considered to be reliably judged against the published level descriptors, it would seem that being able to apply the particle ideas taught to all is a characteristic that can be expected of only a minority of students.

\section{Rationale for study}

It is within this curriculum context that the study reported here was undertaken. At the time of the data collection (2005), the model scheme of work for KS3 (QCA, 2000) would have been in place when all our informants were taking lower secondary science, and the teaching Framework (with 'particles' as one of its five key ideas) would have applied to all our KS3 (years 7-9) interviewees. The present research was timely, as a new programme of study for science within the ENC at KS4 (upper secondary level) was introduced in 2006, and a revised KS3 (lower secondary) curriculum is being introduced in 2008 (see the Discussion). In both cases the revisions amount to substantive redesigns, rather than peripheral modifications to the previous curriculum requirements.

Over a period of one-and-a-half decades then, a highly specified science curriculum has been introduced, reinforced by National Tests, and then supplemented - first by an official model teaching scheme, and then by a detailed 'Framework' for planning and organising science teaching, supported by an extensive Strategy meant to inform pedagogy. Our study coincides with the end-point of this process of what (in the 
English context) amounts to an unprecedented attempt to regulate the teaching of science. National Testing outcomes suggest that only a minority of English pupils reach the end of lower secondary education with an appreciation of the particle models that are extensively taught as a key component of school science: the present study was an opportunity to investigate this inference by exploring the thinking of a modest sample of English secondary pupils in depth.

\section{An interview study exploring student explanations}

The study reported here was carried out in the [blinded for review] area of England during the second half of the 2004-5 academic year (i.e. March-June 2005). The study was designed to find out how secondary age students would explain a range of demonstrations relating to phenomena commonly met in school science. We explore the ideas students would use in their explanations, and (of particular relevance to this paper) the extent to which they would draw upon particle-based explanations. Given that the National Testing outcomes (discussed above) have consistently suggested that by the end of lower secondary science most students have not reached the 'levels' of attainment consistent with the ability to appreciate and apply the particle ideas that are seen as one of the key organising ideas for teaching and learning lower secondary science, the present study explores the extent to which a sample of secondary students were able to apply particle ideas in interviews.

\section{Methodology}

Data were collected for this study using semi-structured interviewing techniques with secondary students. Educational research has commonly been characterised as being of two main types, sometimes labelled as distinct paradigms (Gilbert \& Watts, 1983), sometimes described as positivist-interpretative or more simplistically quantitativequalitative. Within a 'post-positivist' view of research, such as that advocated by the US National Research Council (NRC, 2002), a broad range of methodologies can contribute to a programme of research (Author 1,2007 ). Our interview study is intended to complement the more representative but necessarily coarse-grained findings of the National Tests. The choice here of what is effectively a qualitative research technique was made because of the desire to investigate student thinking in depth, probing their own ways of describing and explaining phenomena (Author1 
2006). Such idiographic approaches have long been recognised as necessary for finegrained exploration of students' ideas (Osborne \& Wittrock, 1985; Pope \& Denicolo, 1986; Smith, diSessa \& Roschelle, 1993).

The present study used demonstrations, supplemented by questions about familiar everyday phenomena (e.g. the spreading of cooking smells). The use of simple demonstrations (e.g. mixing two liquids) is an example of a well-established type of protocol used in science education research, known as 'interview-about-events' (White \& Gunstone, 1992). The demonstrations were carried out by the second author, and used as foci to elicit explanations. A repertoire of demonstrations was developed (detailed below), but as interviews typically lasted about 30 minutes (a reasonable time to maintain student interest and concentration), only a selection of Deleted: 20demonstrations could be included in each interview. Audio recordings were made of the interviews, and these were later transcribed for analysis.

The repertoire of demonstrations/scenarios used across the study comprised:

1. Dissolving potassium permanganate: Adding a crystal of (highly coloured) potassium permanganate in a beaker of water

2. Dissolving salt: Adding a pinch of salt in a beaker of water, and observing over time

3. Recovering solute: Asking about the possibility of recovering the dissolved salt from 2.

4. Evaporating water: Asking about what happens when water evaporates upon heating.

5. Stretching wire: Apply force to a small piece of metal wire. Asking what would happen if the wire was heated.

6. Compressing gas: Compressing a sample of air in a plastic gas syringe.

7. Ice melting: Asking about what happens when ice melts.

8. Floating ice: Asking why ice will float when added to a glass of water. 
1

2

3

4

5

6

7

8

9

10

11

12

13

14

15

16

17

\author{
9. Diffusing smell: Asking how the smell of food can be detected in rooms well away \\ from the kitchen where the food is cooked. \\ $\underline{\text { 10. Miscible liquids: Adding equal volumes of water and ethanol and observing the }}$ \\ volume of the resultant mixture. \\ $\underline{\text { 11. Diffusing pigment: Adding a few drops of food colouring (a solution of pigment) }}$ \\ $\underline{\text { to a beaker of water. }}$ \\ 12. Precipitation reaction: Adding a small volume of silver nitrate solution to sodium \\ chloride solution. \\ 13. Neutralisation reaction: Adding volumes of alkali to a solution of acid containing \\ an indicator.
}

14. Combustion reaction: Lighting-up an alcohol burner and asking what happens.

\title{
15. Insoluble solid: Adding sand to a beaker of water
}

16. Immiscible liquids: Adding some drops of oil to a beaker of water.

The intention was to explore student explanations in a range of different contexts where particles ideas could be applied. The demonstrations were examples of physical changes, mixing (or not) and dissolving, and of chemical changes, that link to the teaching objectives in the Framework (DfES, 2002, see Figure 2). For example, Deleted: II Deleted: 'science' Deleted: , Deleted: the idea of Deleted: and coloured and non-coloured solids were used to investigate dissolving (a focus of year 7 teaching objectives), compressing air in a syringe directly links with a year 7 Deleted: Compressing objective to teach why solids and liquids are much less compressible than gases, and the demonstration of spreading of food dye in water relates to another objective for year 7 to teach why diffusion occurs in liquids and gases. Teaching particle models of chemical reactions appears in both Year 8 and 9 objectives.

Similar phenomena have been used in previous studies: for example, Novick \& Nussbaum (1981), reported using air in a sealed syringe to investigate about air compressibility, Needham \& Hill (1987) reported using a copper sulphate crystal placed in water as an example of dissolving (we used potassium permanganate in the 

examine students' ideas about chemical reactions.

As described below, we worked with a convenience sample. We looked to recruit a varied sample by including several schools and asking for interviewees across the ability range, We describe the nature of our sample below, offering readers the opportunity to consider whether our findings can be considered relevant to wider contexts, i.e. reader generalisation (Kvale, 1996; Eybe \& Schmidt, 2001).

\section{Sample}

Data were collected during interviews with secondary students, from 5 schools (see Table 1). The schools were co-educational state schools (three in the City of [blinded for review] and two in adjacent villages) where the teaching of the ENC was compulsory. The schools that were invited to participate in the study all had links to the Faculty of Education in [blinded for review], and were considered to offer examples of good practice in terms of teaching and professional development. In some (seven) of the early interviews we talked to dyads of students from the same age group/class, to allow peer interactions (cf. Gilbert \& Pope, 1986), but in effect found that there was little interaction, but rather alternation of exchanges between the interviewer and the two students. We decided early in the fieldwork, therefore, to use single respondent interviews for the rest of the study (see Table 1).

It is recognised that curriculum reform is a slow and complex process that can be impeded, frustrated or misdirected by a wide range of factors (e.g. Anderson, 1996). Whilst English schools are required to teach the prescribed curriculum, they have flexibility in responding to curriculum 'guidance' such as the Framework (DfES, 2002) and other outputs from the Strategy. The five schools where our data were collected demonstrate this, so that the individual departmental schemes of work reflected, but did not necessarily directly adopt, the full model scheme issued by the curriculum authority (e.g. QCA, 2000).

One of the five schools (school 1) where we collected data reported that they did not explicitly use the Framework (DfES, 2002), or any other Strategy resources (despite $\underline{\text { schools being given funding resources to access the associated training). However, }}$ 
this school had adopted a commercial teaching scheme (called 'Framework Science') claimed by its publishers to be "perfectly in line with the approach and content of the Framework and QCA Scheme of Work" (http://www.oup.com/uk/catalogue/?view=oxed\&ci=9780199148967, accessed 14/01/2008), suggesting a strong indirect influence.

The other schools involved in the study used commercial teaching schemes that could be considered to be modified versions of the recommended model. These schools engaged with the Strategy programme of teacher support for the recommended Framework (DfES, 2002). The (then) Head of Science in one of the schools (school 4) described how departmental staff had undertaken "extensive training in all aspects of the KS3 Strategy" which was considered to have "had a big impact on the achievement of our pupils and improving standards".

The non-mandated nature of official 'guidance'; the tendency for most schools to wish to show they have been following what is set out as 'best practice'; and the indirect ways in which such officially sanctioned advice can influence practice make it difficult to establish a clear picture of the precise influence of the government initiatives on the learning of students. Observing the extent to which teaching actually adopted the recommended approaches was beyond the present study. It seems reasonable to assume that actual classroom practice in England reflects government 'guidance' to differing degrees, which seems to be the case in the schools involved in the present study.

A desire to include students across a range of year groups and from several institutional contexts was moderated by pragmatic constraints (relating to when school colleagues could host research visits). Students were nominated by their class Deleted: I Deleted: concerns Deleted: volunteers, teachers as being willing to spend time being interviewed, selected from across the ability range.

Our decision not to limit the study to those students identified by their teachers as more able was a principled one, in view of the common programme of study set out in the curriculum for all students where, learning about particle models is prescribed for all students ${ }_{k}$ Interviewing only those learners offering their assistance was considered important both to ensure validity of responses (Stahly, Krockover \& Shepardson,

Deleted: . That is, whilst
differentiation by outcome is
recognised in the National
Curriculum in terms of 'levels'
exemplified by increasing degrees of
sophistication in the thinking being
demonstrated by students
(DfEE/QCA, 1999, see
Deleted: the Discussion,
below),
Deleted: none-the-less
Deleted: II


1999) and to meet ethical principles (Author1, 2002b; DiCicco-Bloom \& Crabtree, 2006)

Table 1: The spread of students interviewed across schools and

$$
\text { year groups }
$$

\section{Data analysis}

There were two stages in the analysis of data. The first stage used an iterative opencoding procedure, similar to that reported by Renström et al. (1990) in their study discussed above. Data were initially coded in descriptive ways, breaking up transcripts into basic units, before looking to develop theoretical categories that reflect ('emerge from') the data. This round of analysis provided insights into the way the students were constructing their explanations based upon a mixture of 'intuitive' notions and taught scientific concepts. The findings of this stage of the analysis (Author2, 2005; Author2 \& Author1, 2006; Authors, accepted for publication) are not reported in depth here.

We then considered the specific question of the extent to which the student explanations drew upon the 'key idea' of particles, and whether particle-based explanations elicited matched the scientific models presented in the curriculum. The second stage of analysis involved classifying segments of interviews into a number of categories, in a similar manner to that used by Johnson (1998a) in his study discussed above.

For this purpose we developed a four-fold classification scheme, to categorize the explanations given in each of the episodes:

$\mathrm{N}$ : no explanation offered

M: an explanation is offered, which does not call upon particle ideas (i.e. a 'macroscopic' or 'molar' level explanation)

P1: an explanation is offered in terms of particle ideas, but is not considered to offer a scientifically acceptable response (in terms of the models taught in the curriculum) 
P2: an explanation is offered in terms of particle ideas, which is considered to be a scientifically acceptable response (in terms of the models taught in the curriculum)

Our scheme is similar to (though simpler than) the models offered by Renström et al. Deleted: to (1990) and Johnson (1998a), but does not seek to offer fine graduations on student responses. For our present purposes all explanations which called upon particles, but which we judged to demonstrate alternative conceptions, were classified together without discriminating specific deviations from the models presented in the curriculum. The scheme will be illustrated in terms of illustrative examples of student responses in each of the classes of phenomena demonstrated.

We have analysed transcripts by episodes, where an episode reflects the recorded dialogue about a particular demonstration. As the examples we quote will suggest, some student comments could be considered ambiguous in terms of how they were using particle notions, so in making assignments we have attempted to interpret specific statements within the wider context of a students' comments within a particular interview episode. For those interviews where pairs of students were interviewed, we have included ratings where the substantive response was from a single student, or where the contributions of both students fitted the same rating. We have tidied extracts from transcripts to increase readability.

\section{Findings}

The number of episodes in each interview varied according to how much depth the students were able to offer in explaining their ideas. An intention to discuss a variety of different phenomena where possible (we offer a simple classification of the phenomena into five grouping below) was modified in situ, in response to student comments (for example to find out whether a similar explanation would be given in a context that was comparable from the scientific perspective). Table 2 offers an overview of the data, showing which phenomena were discussed in the different interviews, and how student responses were rated for each episode. 
There were just over two hundred and twenty discrete episodes in the database (see

Deleted: II

Table 2). We now illustrate the range of student's answers, by discussing some examples under five broad classes of phenomena: dissolving; physical changes; mixing; chemical reactions; and immiscibility. This classification reflects similarity of phenomena from a scientific perspective. For example, adding food dye to water is considered under the 'mixing' category as this used a solution of dye that had already been dissolved in a solvent.

Deleted: , relating to Deleted: changing state

\section{Explaining dissolving}

The demonstrations used here were: adding a pinch of table salt or sugar to tap water and waiting for it to dissolve, and asking about the possibility of separating the solution; and adding a crystal of potassium permanganate to water and waiting for it to dissolve to give a strongly coloured solution.

Deleted: 2

Table 3: Classification of students' explanations of dissolving

There were 89 interview episodes where students were asked to explain aspects of dissolving (see Table 3 ). In 6 of these episodes the students were not able to offer any kind of explanation (category N). Of the other 83 episodes, 27 were categorised as M. An example of a student response categorised as $\mathrm{M}$ came from a year 8 student from school 3 (designated student 5, S5), who suggested that when salt was added to water: 
S5: The water is kind of making [the salt] smaller and smaller

I (Interviewer, Author2): How is it that the water makes it become smaller and smaller?

S5: Is there something in the water that makes it, that reacts with the salt, [something that] kind of just makes it smaller and smaller?

I: What do you mean by reacting?

S5: When it is salt and sugar and stuff I don't know, it makes the salt melt, but like in a kind of way, not with the heat. Just eventually it will just dissolve, you can still taste in the water, but you cannot see it - it is invisible, but it is still there.

We see that S5 refers to the observable phenomena of grains getting smaller during dissolving. She is aware that although the solid seems to disappear, it is still present in a sense, and can be detected in the taste of the solution. However she does not explain this with particle ideas. In particular she refers to a 'reaction' and to 'melting'. From her observations, dissolving is not so different to chemical reactions (where substances 'disappear') or melting (where a solid substance becomes a liquid form of the same substance). In scientific terms these are very different processes to each other, and to dissolving: something that is very clear when these processes are modelled in particle terms, but less obvious from simple observation.

Another example of a response categorised this way was elicited from a Y10 student from school 5, designated S34. Here we see S34 use a suitable technical term, 'diffusion', to explain why the colour of the potassium permanganate spreads through the water. However, he explains this in terms of the solid being 'softened' by the water, rather than drawing upon a mental model of what was happening at a particle level.

I: Observe what happens. Describe and try to explain, what is happening in there?

S34: It's diffusing, I think.

I: How do you think this happens?

S34: Cause the water like wets it, then it like spreads. The crystal is hard and if you wet it, then it is soft and spreads.

Even when students do refer to particle models, they may not be able to apply them in a scientifically acceptable way. S17, a Year 9 student from school 3, provides an example of a student response categorised as P1: 
A smaller number of students had made more progress in developing their

Deleted: 2 using these assigned properties to explain macroscopic events. 49 of the episodes were categorised as P1 (Table 3). understanding of particle models, to a point where their explanations drew upon particle ideas in ways that better fitted the ideas taught in the secondary curriculum. Seven episodes were categorised as P2. An example of a student response categorised as $\mathrm{P} 2$, was a Y9 student from school 2, S12:

I: So, what's happening in there and why do you think it's happening that way?

S12: It's dissolving in the water

I: What do you mean by dissolving?

S12: The chemicals, I mean the particles in the potassium perman-, whatever, is sort of mixing in with the particles in the water, but they are not sort of joining, just mixing. Eventually the water will be all purple

I: Why is that?

S12: Because the particles sort of, spread as far as they can, they will all be mixed with water.

So S12 was able to relate the observable phenomena of the spreading colour to both the concept of dissolving and an acceptable scientific model she had learnt about how 
particles of substances become mixed when a solute dissolves in solvent. One Y10 student from School 5, produced a 'P2' category explanation of salt dissolving, that included reference to the idea of a saturated solution explained in particle terms:

S39: The salt is soluble and the water takes part of the salt and then the particles mix together with the water, but then when there is too many salt particles in there, the salt could stop breaking up and there would be salt granules left at the bottom. If you heat it up, it might speed up, leaving no granules. But if you keep doing it for a very long time, eventually you couldn't dissolve any more salt into the water, it would be left at the bottom.

This is an example of effective coordination of the use of particle models with scientific descriptions of processes at a macroscopic level. This is the level of

knowledge and understanding sought in secondary science teaching, but which the

Deleted: many majority of the students interviewed did not demonstrate.

\section{Explaining physical changes,}

The same categories of responses were used to analyse the other interview episodes, and a similar range of responses was found. So to explore student thinking about changes of state, or of state functions demonstrations were used of evaporating water, stretching a small piece of metal and compressing air in a sealed syringe. These phenomena are here classed together as they are simple reversible physical changes. Students were also asked what happens when jee melts, why it is that ice floats in water, and how we can smell an odour some distance from its source.

Table 4: Classification of students' explanations of physical

\begin{tabular}{l} 
Deleted: physical changes (i.e. \\
\hline Deleted: such as pressure \\
\hline $\begin{array}{l}\text { Deleted: - the problematic } \\
\text { nature of the physical-chemical } \\
\text { change distinction is considered in } \\
\text { the Discussion below), } \\
\text { demonstrations }\end{array}$ \\
\hline Deleted: water \\
Deleted: freezes \\
Deleted: 3
\end{tabular}
changes

The database contained 48 interview episodes relating to this class of phenomena

(Table 4). There was only one episode where the student was unable to offer an

Deleted: 3 explanation $(\mathrm{N})$, and only eight where particle ideas were not used $(\mathrm{M})$. An example Deleted: were of such a response was that of student S2, a Y7 student from school 1. She explained that when water is heated "you get bubbles, it boils", and that before it boils "it gets hotter and hotter and steam comes out and then it starts to bubble". A Y8 student from the same school, S11, provides an example of an explanation referring to particles, but not in a scientifically acceptable way (i.e. P1). According to S11, "The water 
would evaporate, the particles expand, but I'm not really sure how". He thought that "if you heat water then the particles...like grow bigger", although he admitted some doubt about the process.

There were 14 episodes categorised as P1, whereas most (25) of the episodes relating to this class of phenomena were categorised as P2. For example, S34, a Y10 student from school 5 freely referred to molecules, and described how when water was heated "they evaporate, go into the air, join the air, until they cool down and condense...it's like individual particles split up, instead of being a group with lots of them, you have individual ones". Although technically the molecules should not be said to evaporate and condense (these terms describe behaviour at the macroscopic substance level), S34 appeared to have well developed mental models of phenomena in terms of particles. S45, a Y11 student from school 1, also explained: "they [water molecules] are still the same compound, it's still $\mathrm{H}_{2} \mathrm{O}$, but in a different physical state [where] they have less attraction to the other particles in this substance".

\section{Explaining mixing}

Another context used was that of mixing. The demonstrations used here included adding equal volumes of ethanol and water and asking why is it that the total volume was not conserved (i.e. due to the strong interactions between the different molecules), and adding a few drops of food dye to tap water.

Deleted: 4

\section{Table 5: Classification of student explanations of mixing}

There are 31 episodes categorised for this class of phenomena, and in this case all students provided explanations (see Table 5). Ten of the responses did not refer to Deleted: 4 particle ideas and were classified as M. For example S9, a Y8 student from school 3: 
I: now that you have seen that [the total volume] has changed, how would you explain it?

S9: It might have air trapped in it, that was trapped in the measurement thing you had and it lost its air while being transferred.

[The mixture is shaken, and the volume decreases further.]

S9: You get rid of the excess air by shaking it. It is bubbling now so it is the air.

S9 explains the non-conservation of volumes in macroscopic terms, arguing that ethanol and water have air trapped in them, which is released on mixing - a conjecture apparently then confirmed when bubbles form as the mixture is shaken. S9's suggestion has merit. Air dissolved in water may be 'degassed' when another substance dissolves. This can be demonstrated in the school laboratory, but requires careful setting-up and close observation (Author1, 1985). A simple explanation would Deleted: ly consider the particles of the new solute fitting between water particles where the air particles had been. Despite the merit of her idea, S9 did not attempt to offer any kind of particle-based explanation.

19 of the episodes were categorised as level P1. So S23, a Y9 student from school 5, offers an explanation of food dye mixing with water that refers to particles, $\underline{\text { but }}$ without doing so in a scientifically acceptable way. She talked of how the food dye "would merge with the water particles". This could just be a poorly phrased attempt at explaining mixing at the particle level. However, when making a comparison with dissolving salt, she suggested,

"it's slightly different since the salt particles are solid and the dye is a liquid. The dye is slowly reacting but in a slightly different way. They both merge, kind of together you can see the green dye but you can't see the salt without a microscope".

She thought that "with a magnifier you could see, but you would see the dye merged with the water". There are a number of technical errors here - confusing mixing with a reaction; considering particles to be solid or liquid (so that salt particles are judged 'solid' in the solution), and expecting the 'merging' of food dye with water to be on a scale that is visible if magnified.

By comparison, a Y10 student from the same school, S39, seemed to appreciate how 
"particles of the food dye are going to spread into the particles of the water and it is going to mix colour. It's different particles, in between the water, and then the food [dye] colour. You can't change the colour of the water particles".

This was one of only two episodes categorised at level P2.

\section{Explaining chemical reactions}

Another context used in the interviews was that of chemical reactions. The demonstrations used here included: a precipitation reaction (silver chloride formation from sodium chloride and silver nitrate solutions): a neutralisation reaction (diluted sulphuric acid and sodium hydroxide reaction in the presence of an indicator to

indicate $\mathrm{pH}$ ); and a combustion reaction (jgniting an alcohol burner). There were 28 episodes for this class of phenomena, and there were no examples where students did not offer an explanation (see Table 6 ).

Table 6: Classification of student explanations of chemical

Again some students did not seem to refer to particle ideas in their explanations (i.e.

six episodes were categorized M, see Table 6). So a Y8 student from school 3, S5, suggested "some kind of reaction because it changed colour", but could offer no further explanation beyond noting that the immediate reaction showed "they've must [have] like mixed immediately". When prompted to talk about the phenomenon in particle terms, she declined: "oh, no, I'm not doing that". By comparison a Y9 student from school 2, S13, was happy to talk about particles, but explained the precipitation reaction in terms of the original reactant salt being "still in there pushed down by the water molecules, but now it's joined by these molecules". This response was one of 19 categorized as P1.

Explaining chemical changes requires a more sophisticated type of particle model than suffices for explaining phenomena such as mixing and changes of state. There were only three_episodes categorised as showing this higher level of understanding (P2), such as the Y8 student from school 3, S9, who described how "the silver particles in the silver nitrate [are] reacting with the salt and creating something new in the reaction". This is not a thorough description in terms of particles, but 
acknowledges that a new substance results from interactions at particle level. $\mathrm{He}$ recognised that the precipitate (which is initially suspended in the reaction solution, and may take some time to sediment out) was not still part of the solution itself: "because the white stuff almost seems as if it is kind of a solid, within a solution".

\section{Explaining non-mixing}

The final class of phenomena demonstrated concerned situations when mixing did not take place, such as an insoluble solid in water (sand was used) and immiscible liquids (shown by adding oil to water). There were 27 episodes relating to this class of phenomena, and only one example of students being unable to offer some kind of explanation (Table 7).

Deleted: 6

Deleted: 6

Over half (16) of the episodes produced explanations that were categorised as not involving particle ideas (M, see Table 7 ). An example would be that of a Y99 student from school 4. When asked about oil added to water, S29 correctly observed that "it just floats", something he attempted to explain in terms of trapped air: "when the oil was added, there was air in the bubbles, so when they hit they're just absorbing all the air from the bubbles and since they are in the water they can't get up". An example of one of the nine episodes categorised as P1 would be from another Y9 student, S12, from school 2, who did use the idea of particles when explaining why sand, unlike salt, was insoluble. She thought this was because "the particles are too big to dissolve in the water". Finally, the only example of a student explanation that was considered to use particle ideas in a scientifically satisfactory way (i.e. classified P2) was provided in an interview with a Y11 student from school 1. Student 43 suggested:

"maybe, I'm going to be wrong here, I'm going to say the particles are not attracted to each other, because most particles have a charge on them, and maybe, like, maybe the oil is not the same charge as the water".

The explanation is tentative, and technically incorrect, but was judged to apply the taught curriculum models. 


\section{Discussion}

Considering all five classes of phenomena demonstrated, there are 223 episodes in the database (see Table 8, cf. Table 2), and students offered explanations in 215 episodes (i.e. 8 were categorised as $\mathrm{N}$ ).

Deleted: 7

Figure 3: Classification of interview episodes by use of particle ideas in student explanations

The only class of phenomena where the students in our sample were generally able to

offer acceptable responses was that of physical changes (see Table 4). This is not obviously the simplest class of phenomena to explain, and it may seem odd that students seemed to find mixing (for example) a more challenging class of phenomena to explain with particle ideas. However, this finding may relate to how the particle model is commonly introduced in the context of teaching about the states of matter (see figure 1) - and then subsequently applied in various other contexts.

$\lfloor$ our study we found that a majority of students were familiar enough with the Deleted: Limitations of the study concept of particles, and were generally happy to talk about phenomena in these terms. It seems that in the context of the then extant version of the ENC it was not the case that most students failed "to invoke atoms and molecules as explanatory constructs" (Hesse \& Anderson, 1992: 277). 
Yet we also found limited appreciation of the way that scientists use particle models to explain the properties of materials in terms of the distinct conjectured properties assigned to the molecules, ions and so forth. So where students did call upon particle ideas, they commonly assigned particles the macroscopic properties to be explained, as has been noted in previous studies (e.g. Author1, 2001). So our study reflects the findings reported in the literature reviewed earlier (Nussbaum \& Novick, 1982; Ault et al, 1984; Ben-Zvi et al, 1986; Briggs \& Holding, 1986; Wightman et al, 1986; $\underline{\text { Renström et al, 1990; Griffiths \& Preston, 1992; Author1, 2001), showing that even }}$ when students use particle ideas, they have considerable difficulty in doing so in $\underline{\text { scientifically accepted ways. }}$

\section{Generalising from the study}

We interviewed a convenience sample of secondary students from a small number of schools in one geographical area. The nature and size of the sample do not allow us to offer views about school differences, and we clearly do not claim that the sample can be seen as fully representative of secondary students following the ENC, even in this one geographical area. Although our sample is spread across the secondary age range (see Table 2), the nature of the sample does not allow us to make reliable comparisons between year groups. The timing of our study is also significant here, undertaken during the third year of the Framework initiative. We would expect the influence on students in years 10 and 11 to be less, as they will have started their secondary education before the Framework was recommended.

\section{Table 2: Classification of interview episodes by year group}

Practical limitations of the time pupils were available for interviews meant that a subset of phenomena was explored in each interview (typically four different demonstrations per interviewee). Although the nature of the interviews gave every opportunity for students to explain their ideas, we can not be sure we always accessed their most sophisticated thinking, and it is possible we may sometimes have misinterpreted their intended meaning (especially as our concern was the nature of their conceptions, regardless of technically correct language).

Despite these provisos, we feel it is significant that our findings from this interview study reflect the inference we drew earlier from the outcomes of National Testing, i.e.

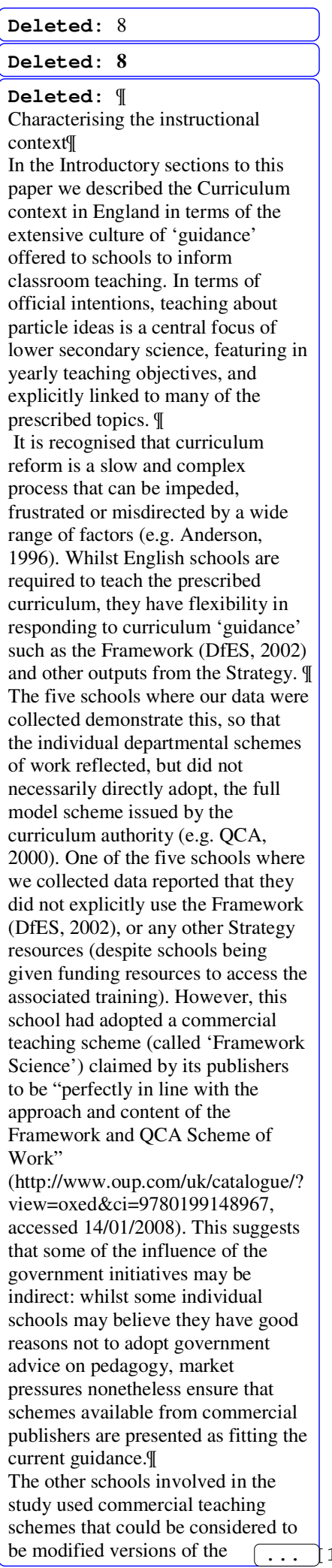


that the majority of students in English schools reach the end of lower secondary science without a good grasp of the nature of one of the key ideas used to organise teaching and learning during that stage of school science. Further, this lack of understanding also seems common among upper secondary students (see Table 9) where teaching is expected to build upon a basic understanding of particle models.

It would seem that there continue to be widespread difficulties in learning particle ideas in secondary science, even in a context where considerable attention has been given to prioritise, support and direct teaching in this topic. We conclude that the

Deleted: suggestive, indicating Deleted: despite the government attemp

Deleted: ts curriculum guidance for those teaching the ENC (DfES, 2002, 2003) has done little to change student understanding in this area since Johnson's study (1998a).

\section{Reflections on the curriculum context}

The approach recommended in English secondary schools is an early introduction of the key ideas, and then regular revisiting in a range of contexts to reinforce, consolidate and develop learning (DfES, 2002, pp.18-19 - see Figure 1). We consider this approach to be a sound response to some aspects of student learning difficulties in this topic, but that, critically, it does not of itself address specific research findings.

There seems little doubt that particle models used in science are highly abstract, and clearly unfamiliar in terms of everyday experience, and these two factors act as potential 'learning impediments' in the topic_(Author, 2005). The official curriculum guidance would seem an appropriate way to ensure that students develop familiarity with basic particle ideas. The students in our sample were indeed largely familiar with particle ideas and generally confident enough in their knowledge to make efforts to use them. In some cases the recommended teaching approach appeared to be reflected in student thinking. S23, a Y9 student from school 5, reported that the particles idea "makes sense" to her, as "you learn it from young and then when you get older they explain it more and more". However a Y10 student from the same school, S35, whilst acknowledging his familiarity with particles, did not see how particle ideas could help him understand phenomena: "sometimes you learn it because you have to learn it, but you don't understand it".

That we found most students showed familiarity with particle ideas but limited understanding is consistent with much previous research. Studies of students' thinking

Deleted: of 
in this area have repeatedly shown that many learners can readily adopt the idea of everything being made of particles, and are often happy to discuss phenomena in these terms. Unfortunately, however, this research also shows that aspects of the scientific models are not just unfamiliar to learners but counter-intuitive - for example the idea that there is nothing between the particles in a hard solid, and that these

We do not wish to be over-pessimistic here. With Renström et al, we recognise that many learners can and do move through a succession of understandings that progress towards scientific models. Johnson's research suggests that where a basic particle model was presented early in lower secondary science, and revisited and developed, students could make significant progress over a three-year period.

Unfortunately, one key recommendation from Johnson's work has not been taken-up in the English curriculum. Particle ideas are revisited regularly in the English scheme, but where Johnson warned that students had to have time to master the basic particle model, lower secondary students in England are also expected to progress to more complex models that can explain the atomic basis of the elements, and the nature of chemical changes. This is presumably seen as an imperative in view of the work particle theories are expected to do by the end of compulsory schooling. Yet in applying this curriculum to all students a situation has developed where National Tests suggest that by the end of lower secondary school, most pupils have failed to reach the levels of understanding that reflect the models being taught (DfES, 2006), despite the plethora of teacher development materials and curriculum guidance intended to 'improve standards' (i.e. increase student levels of attainment on the National Tests).

Two possible responses to this situation would be to reduce curriculum demands to better meet what research suggests is achievable for most students, or to differentiate the curriculum for different groups of learners. Learning scientific particle models certainly provides an appropriate challenge for the most able learners (Georgousi, Kampourakis, \& Tsaparlis, 2001), but is clearly leading to confusion for many others. To some extent the English curriculum context described here may well be shifting in this latter direction. The revisions of the curriculum being introduced specify much 
The heart of the cultural contribution of science is a set of major ideas about the material world and how it behaves, such as the particle model of matter... It follows that these ideas and themes should be prominent within the science curriculum.

(Millar \& Osborne, 1998: §5.2.1)

If particle ideas are to remain central to the curriculum for all learners then our study suggests that current teaching approaches will leave many students confused. Instead more effective pedagogy needs to be developed.

Like Johnson before us, we wish to remain optimistic. Renström et al's (1990) work suggested that common alternative conceptions of particles could fit within a conceptual trajectory leading towards target knowledge and understanding. Johnson (1998a) showed that at least part of this model does represent a progression pathway at lower secondary level. The key problem seems to be the rate at which students progress through this pathway, which for many students is insufficient to allow a suitable 'basic' particle model to be developed early enough to offer robust foundations for further learning (about atoms, molecules, ions etc.).

The same problem seems to recur among the minority of students who are able to successfully demonstrate this progression during the compulsory school years, when they meet orbital models of the atom in college courses (Author, 2005). The educational challenge, then, is to accelerate student progress through the sequence of conceptual models used in school and college science.

The Framework used in lower secondary education in England (DfES, 2002), which we have characterised as early introduction followed by frequent review, does not seem to meet this challenge. Whilst the sequencing of content may appear logical to 
subject experts, it fails to appreciate the complexity of the material presented from the perspective of most students' prior knowledge (Johnstone, 2000; Author1, 2002).

As one example, the Framework (DfES, 2002) recommends that teachers use a simple particle model to explain solution phenomena such as how the rate of dissolving depends on temperature, and saturated solutions, in the first year of secondary school. The assumption seems to be that dissolving is a straightforward phenomenon when considered in particle terms. However students' explanations confusing dissolving with chemical reaction, reported above, act as a useful reminder of how even such a supposedly 'simple' phenomena can be understood at different levels of complexity. This class of 'physical' change involves the breaking and formation of bonds between particles (usually considered characteristic of 'chemical' changes), and in the case of ionic solutes, indeed, the breaking of strong chemical bonds (Author 1, 2002).

It is of note in this particular context that one of the yearly objectives listed in the Framework under the key idea of particles (see Figure 2) is to teach year 9 pupils to "identify evidence which indicates that a chemical reaction has taken place, such as the association of energy transfer with chemical change". This macroscopic indicator links to bond breaking/formation, and also to the entropy changes associated with mixing, cystallisation/precipitation, solvation etc. Perceptible energy transfers can occur when ammonium salts dissolve, when oleum is mixed with water, or when steam condenses - all changes that are considered 'physical' on a simplistic physicalchemical changes dichotomy. Our feeling here is that the designers of the Framework (DfES, 2002) have failed to fully consider the teaching and learning implications of the objectives that set out target knowledge for all 14 year-olds in England.

This is reflected too in the Strategy materials designed to support teachers (Key Stage 3 National Strategy, 2003a, 2003b). Whilst there is much emphasis on where students go wrong, characterised as their 'misconceptions', and the importance of taking these ideas into account, there is limited engagement in ideas from research about the nature and origins of learners' ideas. Recommending that teachers develop activities to overcome learners' misconceptions, without understanding how and why students come to think in the ways they do, offers teachers a very limited basis for planning teaching that can support conceptual change. Understanding the 'learning demand' (Leach and Scott, 2002) is not only about identifying how pupil thinking is at odds 
with target knowledge, but also appreciating what is channeling current thinking

(Author, 2005). We suspect that an approach drawing more heavily upon well-

developed constructivist principles (Author1, 2006) might have more success.

If students are constructing their understanding of 'particles' such as molecules and grains and specks, supported by concrete models (Harrison \& Treagust, 1996) that are inevitably fabricated from macroscopic materials, then it is not surprising that they are commonly missing the major ontological distinctions so central to the particle theories of science (Author1, 2001). However, we suspect that students may well have other conceptual resources (Hammer, 2004) that are more suitable for developing appropriate (i.e. scientific) notions of particles. We are encouraged by the findings of Ault, et al (1984) who reported that understanding about molecules evolved more rapidly from a rich conceptualisation, even when this included a range of idiosyncratic 'alternative' conceptions.

Our analysis of students' explanations identified a number of apparently intuitive ways of thinking about phenomena at the level that diSessa (1993) has described as 'phenomenological primitives' (Author2, 2005; Author2 \& Author1, 2006; Authors, accepted for publication). DiSessa (1993) suggests that the human conceptual system uses a wide range of these 'p-prims', which operate in perception to recognise phenomena in terms of basic patterns. DiSessa described p-prims as "primitive elements of cognitive mechanism - as atomic and isolated a mental structure as one can find" (p.112). Where conceptions are specific notions that are of the form of propositions ('giraffes have long necks because their ancestors had to stretch for juicy leaves', 'inert gases do not react because they have stable electronic configurations', 'the sun pulls the earth more than the earth pulls the sun'), p-prims are primitive in the sense of acting at an early (preconscious) stage of cognition, and "act largely by being recognised in a physical system or in the system's behaviour or hypothesized behaviour" (diSessa, 1993: 111), that is by identifying phenomena as matching common general patterns.

In effect they provide a repertoire of fundamental cognitive elements from which our mental models of the world are constructed. From this perspective, teaching can in 
principle take advantage of p-prims by channelling students towards the most productive available ways of perceiving new ideas.

Whilst this must at present be considered a tentative suggestion, we do feel there should be further research to explore the potential of this approach. If progression through a sequence of models could be guided by linking with basic intuitions about the world, then pedagogy could indeed be developed to accelerate learning about

Deleted: in press particles during secondary education (Author 1,2008 ).

\section{Conclusions}

We have investigated the extent to which students could explain basic physical and chemical phenomena using particle ideas. This is an important focus because the particle concept is absolutely fundamental to understanding much of modern science, but previous studies have repeatedly demonstrated that this topic leads to such considerable learning difficulties that students frequently develop their own alternative conceptions inconsistent with the scientific models. This topic therefore offers a significant challenge to those designing science curricula and teaching schemes.

The English curriculum at the time of our study (DfEE/QCA, 1999) has provided an opportunity for exploring student thinking in an educational context where particles have been given particular emphasis in secondary science. Curriculum guidance had identified 'particles' as one of five 'key ideas' which should be used to organise and structure learning in lower secondary science (DfES, 2002). There had been considerable investment in supporting teachers to adopt such recommendations in terms of professional development and the dissemination of teaching and guidance materials (e.g. DfES, 2003).

Despite this, the present study found that most students in our sample were not able to use the particle model to provide explanations that matched scientific thinking. If our findings from a convenience sample of secondary students reflect the national situation (as the official National Test findings would suggest), then this approach to teaching about particles in English secondary schools does not offer a satisfactory solution to this educational problem. 
There already exists a good deal of research that indicates why this is a challenging topic, and where students commonly 'go wrong'. This study suggests that the approach of early introduction of particle ideas, followed by frequently revisiting the concept to explain a wide range of contexts does seem to lead to many students using particles as an explanatory device in science, but does not seem to overcome the wellrecognized problem that students commonly misunderstand and misapply particle ideas. It seems likely that progress towards a 'scientific' understanding of particle models will be even slower in many other contexts where basic particle theory is introduced later or where there is less emphasis on opportunities to apply and consolidate learning. This certainly seems to be the case, for example, in Sweden where a much less prescribed curriculum allows teachers a good deal more flexibility in when and how to introduce these ideas (Colleague and Author1, in press).

Whilst our findings suggest the strategy for teaching about particles in the English

Deleted: II

Given that the curriculum context of our present study is one where extensive guidance on this topic is provided to support teaching (DfES, 2002, 2003), it might be considered potentially a 'best case' scenario. Although our findings suggest that among our modest convenience sample the approach used in the English Strategy has not facilitated most students developing appropriate particle models, it

Deleted: much more context has not been entirely successful, we do not see this as surprising, nor a reason for totally abandoning the approach. Our argument here is not that attempts to guide teachers in this area cannot be effective. New teaching approaches need to be carefully planned and piloted, and then properly evaluated once teachers have become familiar and confident in them, Optimum approaches are unlikely to be found Deleted: new approaches immediately, and evaluations should inform cycles of modification and further evaluation. In particular, such approaches must be based on more sophisticated research-informed pedagogy. We have tentatively suggested one direction such research-based curriculum development might take.

Deleted: 457 $(12,809)$

Acknowledgements: Thanks are due to the [blinded for review] and to [blinded for Deleted: I review] for offering the second author a study visit that allowed her to undertake the fieldwork. The authors are grateful to the teachers in the local schools who organized research visits and identified students prepared to be interviewed. Acknowledgement is also given to the valuable suggestions for improving the present paper offered by the anonymous referees. 


\section{References}

Anderson, R. D. (1996). Study of Curriculum Reform. Washington D C: U S Department of Education Office of Educational Research and Improvement.

APU (1989a). Science at Age 13: a review of APU survey findings 1980-84. Assessment of Performance Unit, London: HMSO.

APU (1989b) National Assessment: The APU Science Approach, Assessment of Performance Unit, London: HMSO

Ault, C. R., Novak, J. D., \& Gowin, D. B. (1984). Constructing Vee maps for clinical interviews on molecule concepts. Science Education, 68 (4), pp.441-462.

Barker, V. \& Millar, R. (1999) Students' reasoning about chemical reactions: what changes occur during a context-based post-16 chemistry course? International Journal of Science Education, 21 (6), pp. 645-665.

Ben-Zvi, R., Eylon, B-S., \& Silberstein, J. (1986). Is an atom of copper malleable? Journal of Chemical Education, 63 (1), pp.64-66.

Briggs, H. \& Holding, B. (1986). Aspects of secondary students' understanding of elementary ideas in Chemistry, full report. Leeds: Children's Learning in Science Project, Centre for Studies in Science and Mathematics Education, University of Leeds.

Brook, A., Briggs, H. \& Driver, R. (1984). Aspects of secondary students' understanding of the particulate nature of matter. Leeds: Children's Learning in Science Project, Centre for Studies in Science and Mathematics Education, University of Leeds.

DES/WO (1988). Science for ages 5 to 16, London/Cardiff: Department for Education and Science/Welsh Office.

DfEE/QCA (1999). Science: The National Curriculum for England, key stages 1-4. Department for Education and Employment/Qualifications and Curriculum Authority.

DfES (2002). Framework for teaching science: years 7, 8 and 9, Key Stage 3 National Strategy, Department for Education and Skills.

DfES (2006). National Curriculum Assessment at Key Stage 3 in England, 2006 (Provisional), Department for Education and Skills, release SFR 34/2006, dated 13 September 2006.

DiCicco-Bloom, B., \& Crabtree, B. F. (2006). The qualitative research interview. Medical Education, 40, 314-321.

diSessa, A. A. (1993). Towards an epistemology of physics. Cognition and Instruction, 10 (2\&3), pp.105-225.

Driver, R. (1983). The Pupil as Scientist? Milton Keynes: Open University Press.

Driver, R. (1989). Students' conceptions and the learning of science. International Journal of Science Education, 11 (special issue), pp.481-490. 
Driver, R., Leach, J., Scott, P., \& Wood-Robinson, C. (1994). Young people's understanding of science concepts: implications of cross-age studies for curriculum planning. Studies in Science Education, 24, pp.75-100.

Education Reform Act (1988). London: HMSO.

Eybe, H. \& Schmidt, H-J. (2001). Quality criteria and exemplary papers in chemistry education research, International Journal of Science Education, 23 (2), pp.209225.

Feynman, R. P., Leighton, R. B. \& Sands, M. (eds.) (1963). The Feynman Lectures on Physics, Volume 1. Reading, Massachusetts: Addison-Wesley Publishing Company.

| Georgousi, K., Kampourakis, C. \& Tsaparlis, G. (2001). Physical-science knowledge and patterns of achievement at the primary-secondary interface, part 2: able and top-achieving students. Chemistry Education: Research and Practice in Europe, 2 (3), pp.253-263.

Gilbert, J. K., \& Pope, M. L. (1986). Small group discussions about conceptions in science: a case study. Research in Science \& Technological Education, 4(1), 6176.

Gilbert, J. K., \& Watts, D. M. (1983). Concepts, misconceptions and alternative conceptions: changing perspectives in science education. Studies in Science Education, 10, pp.61-98.

Grevatt, A., Gilbert, J. K. \& Newberry, M. (2007). Challenging able science learners through models and modeling, in K. S. Taber, (Ed.), Science Education for Gifted Learners, London: Routledge, pp.85-99.

Griffiths, A. K. \& Preston, K. R (1992). Grade-12 students' misconceptions relating to fundamental characteristics of atoms and molecules. Journal of Research in Science Teaching, 29 (6), pp.611-628.

Hammer, D. (2004). The variability of student reasoning, Lecture 3: Manifold cognitive resources. Proceedings of the Enrico Fermi Summer School in Physics, Course CLVI. Italian Physical Society. Available at http://www.physics.umd.edu/perg/papers/papers-ee.htm

Harrison, A. G. \& Treagust, D. F. (1996) Secondary students' mental models of atoms and molecules: implications for teaching chemistry, Science Education, 80 (5), pp.509-534.

Harrison, A. G. \& Treagust, D. F. (2000). Learning about atoms, molecules, and chemical bonds: a case study of multiple-model use in grade 11 chemistry. Science Education, 84, pp.352-381.

Harrison, A. G. \& Treagust, D. F. (2002). The particulate nature of matter: challenges in understanding the submicroscopic world. In J. K. Gilbert, O. de Jong, R. Justi, D. F. Treagust, \& J. H. van Driel, Chemical Education: Towards Research-based Practice, pp.189-212, Dordecht: Kluwer Academic Publishers.

Hesse, J. J. \& Anderson, C. W. (1992). Students' conceptions of chemical change. Journal of Research in Science Teaching, 29 (3), pp.277-299.

Jenkins, E. W. (2004). From option to compulsion: school science teaching, 19542004. School Science Review, 85(313), 33-40. 
Johnson, P. M. (1998a). Progression in children's understanding of a 'basic' particle theory: a longitudinal study. International Journal of Science Education, 20 (4), pp.393-412.

Johnson, P. (1998b). Children's understanding of changes of state involving the gas state, part 1: Boiling water and the particle theory. International Journal of Science Education, 20 (5), pp.567-583.

Johnson, P. (1998c). Children's understanding of changes of state involving the gas state, part 2: Evaporation and condensation below boiling point. International Journal of Science Education, 20 (6), pp.695-709.

Johnson, P. (2000a). Children's understanding of substances, part 1: recognising chemical change. International Journal of Science Education, 22 (7), pp.719737 .

Johnson, P. (2002b). Children's understanding of substances, part 2: explaining chemical change. International Journal of Science Education, 24 (10), pp.10371054

Johnson. P. M. (2005). The development of children's concept of a substance: A longitudinal study of interaction between curriculum and learning. Research in Science Education, 35(1), pp. 41-61.

Johnstone, A. H. (2000). Teaching of Chemistry - logical or psychological? Chemistry Education: Research and Practice in Europe, 1(1), 9-15.

Key Stage 3 National Strategy. (2003a) Strengthening teaching and learning of particles in Key Stage 3 science: Main messages. London: Key Stage 3 National Strategy, Department for Education and Skills.

Key Stage 3 National Strategy. (2003b). Strengthening teaching and learning of particles in Key Stage 3 science: Notes for participants. London: Department for Education and Skills.

Kvale, S. (1996) InterViews: An introduction to qualitative research interviewing, Thousand Oaks, California: SAGE Publications.

Leach, J. \& Scott, P. (2002). Designing and evaluating science teaching sequences: an aproach drawing upon the concept of learning demand and a social constructivist perspective on learning. Studies in Science Education, 38, pp.115142.

Lijnse, P. L., Licht, P., de Vos, W., \& Waarlo, A. J. (Eds.). (1990). Relating Macroscopic Phenomena to Microscopic Particles: a central problem in secondary science education. University of Utrecht: CD-ß Press.

Millar, R. \& Osborne, J. (1998). Beyond 2000: Science education for the future. London: King's College.

MoE (1993). Science in the New Zealand Curriculum. Ministry of Education, Wellington: Learning Media.

NAS (1996) National Science Education Standards. National Research Council of the National Academy of Sciences. Washington DC: National Academy Press.

Needham, R., \& Hill, P. (1987). Teaching strategies for developing understanding in science. Leeds, UK: Centre for Studies in Science and Mathematics Education, Children's Learning in Science Project. 
Novick \& Nussbaum (1981). Pupils' understanding of the particulate nature of matter: a cross age study. Science Education, 65 (2), 187 - 196.

NRC (2002). Scientific Research in Education. National Research Council Committee on Scientific principles for educational research. Washington DC: National Academies Press.

Nussbaum, J. \& Novick, S. (1982). Alternative frameworks, conceptual conflict and accommodation: toward a principled teaching strategy. Instructional Science, 11, pp.183-200.

Osborne, R. J., \& Wittrock, M. (1985). The generative learning model and its implications for science education. Studies in Science Education, 12, 59-87.

Papageorgiou, G. \& Johnson, P. (2005). Do particle ideas help or hinder pupils' understanding of phenomena? International Journal of Science Education, 27 (11), pp. 1299-1317.

Pope, M. L., \& Denicolo, P. (1986). Intuitive theories - a researcher's dilemma: some practical methodological implications. British Educational Research Journal, 12(2), 153-166.

QCA (2000). Key stage 3 schemes of work. Science Unit 7G: Particle model of solids, liquids and gases. London: Qualifications and Curriculum Authority.

QCA (2001). Standards at key stage 3 Science: A report for headteachers, heads of department, science teachers and assessment coordinators on the 2000 national curriculum assessments for 14-year-olds. London: Qualifications and Curriculum Authority.

QCA (2003). Standards at key stage 3 Science: A report for headteachers, heads of department, science teachers and assessment coordinators on the 2002 national curriculum assessments for 14-year-olds. London: Qualifications and Curriculum Authority.

QCA (2004). Programme of study: science Key stage 4. London: Qualifications and Curriculum Authority.

QCA (2005). Science: Changes to the curriculum from 2006 for key stage 4. London: Qualifications and Curriculum Authority.

QCA (2007a). Science: Programme of study for Key Stage 3 and attainment targets. London: Qualifications and Curriculum Authority.

QCA (2007b). The new secondary curriculum. What has changed and why? London: Qualifications and Curriculum Authority.

Renström, L., Andersson, B., \& Marton, F. (1990). Students' conceptions of matter. Journal of Educational Psychology, 82 (3), pp.555-569.

Schmidt, H-J. (1991). A label as a hidden persuader: chemists' neutralization concept. International Journal of Science Education, 13 (4), pp.459-471.

SI (1989) The Education (National Curriculum) (Attainment Targets and Programmes of Study in Science) Order 1989. Statutory Instrument 1989 No. 309. London: HMSO. 
Smith, J. P., diSessa, A. A., \& Roschelle, J. (1993). Misconceptions reconceived: a constructivist analysis of knowledge in transition. The Journal of the Learning Sciences, 3(2), 115-163.

Stahly, L. L., Krockover, G. H., \& Shepardson, D. P. (1999). Third grade students' ideas about the lunar phases. Journal of Research in Science Teaching, 36(2), 159-177.

Stoll, L., Stobart, G., Martin, S., Freeman, S., Freedman, E., Sammons, P., Smees, R., Jones, S., Maw, N., Cuttance, P. \& Muschamp, Y. (2003). Preparing for Change: Evaluation of the Implementation of the Key Stage 3 Strategy Pilot. London: Department for Education and Skills.

Watts, D. M. \& Gilbert, J. (1983). Enigmas in school science: students' conceptions for scientifically associated words. Research in Science and Technological Education, 1 (2), 1983, pp.161-171.

White, R. \& Gunstone, R. (1992). Probing Understanding. London: The Falmer Press.

Wightman, T., Green, P., \& Scott, P. (1986). The Construction of Meaning and Conceptual Change in Classroom Settings: Case Studies on the Particulate Nature of Matter. Leeds: Children's Learning in Science Project, Centre for Studies in Science and Mathematics Education.

Author1 (1985) journal article in School Science Review.

Author1 (2001) journal article in Chemistry Education: Research and Practice in Europe.

Author1 (2002a) book, London: Royal Society of Chemistry.

Author1 (2002b) journal article in British Educational Research Journal.

Author1 (2003) journal article in Foundations of Chemistry.

Author1 (2005) journal article in Science Education.

Author1 (2006) journal article in Studies in Science Education.

Author 1 (2007) book, Sage Publications

Author1 (2008) journal article in Science \& Education

Author1 (2008) journal article in International Journal of Science Education.

Deleted: in press

Author1 \& colleague (1996) journal article in International Journal of Science Education.

Colleague and Author1 (2005) book, London: Routledge.

Colleague \& Author1 (2007) Chapter in international handbook.

Colleague \& Author1 (in press) International Journal of Science Education

Author2 (2005) Seminar paper, available through education-line

Author2 \& Author1 (2006) Paper presented at International Conference

Author1 \& Author2 (accepted for publication) article to appear in Education in Chemistry 


\section{Figure 1: The Framework guidance for teaching all lower} secondary pupils to use particle ideas

"In Year 7, early work on particles should introduce pupils to: a simple model of matter made up of particles; how that model can be used to explain physical phenomena such as diffusion and gas pressure, and changes of state such as melting and solidifying...

Once these aspects have been established challenge pupils to apply their developing understanding of particles to explain other physical phenomena, such as expansion. As they meet a wider range of physical and chemical phenomena, they should develop a more sophisticated view of atoms as fundamental building blocks of matter, and use this new understanding...

At the same time, teach them to recognise the limitations of the simple model of matter...

Pupils will use particles to explain a wide range of physical, biological and geological phenomena, such as the movement of substances through cell membranes, photosynthesis, digestion, and the formation of crystals in rocks. They will also consider how energy is transferred by the movement of particles in conduction, convection and evaporation." 
Figure 2: Teaching objectives for the three years of lower secondary science (from DfES, 2002: 28)

\begin{tabular}{|c|c|}
\hline $\begin{array}{l}\text { Year } 7 \\
\text { pupils } \\
\text { should } \\
\text { be } \\
\text { taught } \\
\text { to: }\end{array}$ & $\begin{array}{l}\text { Describe a simple particle model for matter, recognising: } \\
\text { - the size, arrangement, proximity, attractions and motion of particles } \\
\text { in solids, liquids and gases; } \\
\text { - the relationship between heating and movement of the particles. } \\
\text { Use the simple particle model to explain: } \\
\text { - why solids and liquids are much less compressible than gases; } \\
\text { - why heating causes expansion in solids, liquids and gases; } \\
\text { - why diffusion occurs in liquids and gases; } \\
\text { - why air exerts a pressure; } \\
\text { - why changes of state occur; } \\
\text { - why mass is conserved when substances dissolve to form solutions; } \\
\text { - why temperature increases are likely to result in substances dissolving } \\
\text { more quickly; } \\
\text { - the formation of a saturated solution. }\end{array}$ \\
\hline $\begin{array}{l}\text { Year } 8 \\
\text { pupils } \\
\text { should } \\
\text { be } \\
\text { taught } \\
\text { to: }\end{array}$ & $\begin{array}{l}\text { Use the simple particle model to explain: } \\
\text { - movement of substances through cell membranes by assuming } \\
\text { particles are of different sizes; } \\
\text { - how crystals form and that slow cooling results in the formation of } \\
\text { larger crystals from molten material and solutions. } \\
\text { Describe a more sophisticated particle model for matter, recognising: } \\
\text { - the atom is the basic building block of matter; } \\
\text { - there is a relatively small number of different atoms; } \\
\text { - elements consist of only one type of atom; } \\
\text { - compounds consist of fixed combinations of different types of atoms } \\
\text { that cannot be easily separated; } \\
\text { - atoms and combinations of atoms can be represented by symbols and } \\
\text { formulae. } \\
\text { Use the more sophisticated particle model to explain how chemical } \\
\text { reactions take place. }\end{array}$ \\
\hline $\begin{array}{l}\text { Year } 9 \\
\text { pupils } \\
\text { should } \\
\text { be } \\
\text { taught } \\
\text { to: }\end{array}$ & $\begin{array}{l}\text { Identify evidence which indicates that a chemical reaction has taken } \\
\text { place, such as the association of energy transfer with chemical change. } \\
\text { Recognise that chemical reactions can be modelled by assuming that } \\
\text { atoms can rearrange themselves, and that this can happen in only a } \\
\text { limited number of ways, for example, } \mathrm{A}+\mathrm{B} \rightarrow \mathrm{AB}, \mathrm{AB}+\mathrm{CD} \rightarrow \mathrm{AD}+ \\
\mathrm{CB} \text {. } \\
\text { Use the particle rearrangement model to: } \\
\text { - predict the names and formulae for products that might be formed } \\
\text { from given reactants; } \\
\text { - write word and symbol equations for some simple reactions; } \\
\text { - explain why mass is conserved in chemical reactions; } \\
\text { - explain how acids react with bases and neutralisation occurs }\end{array}$ \\
\hline
\end{tabular}


Figure 3: Classification of interview episodes by use of particle ideas in student explanations

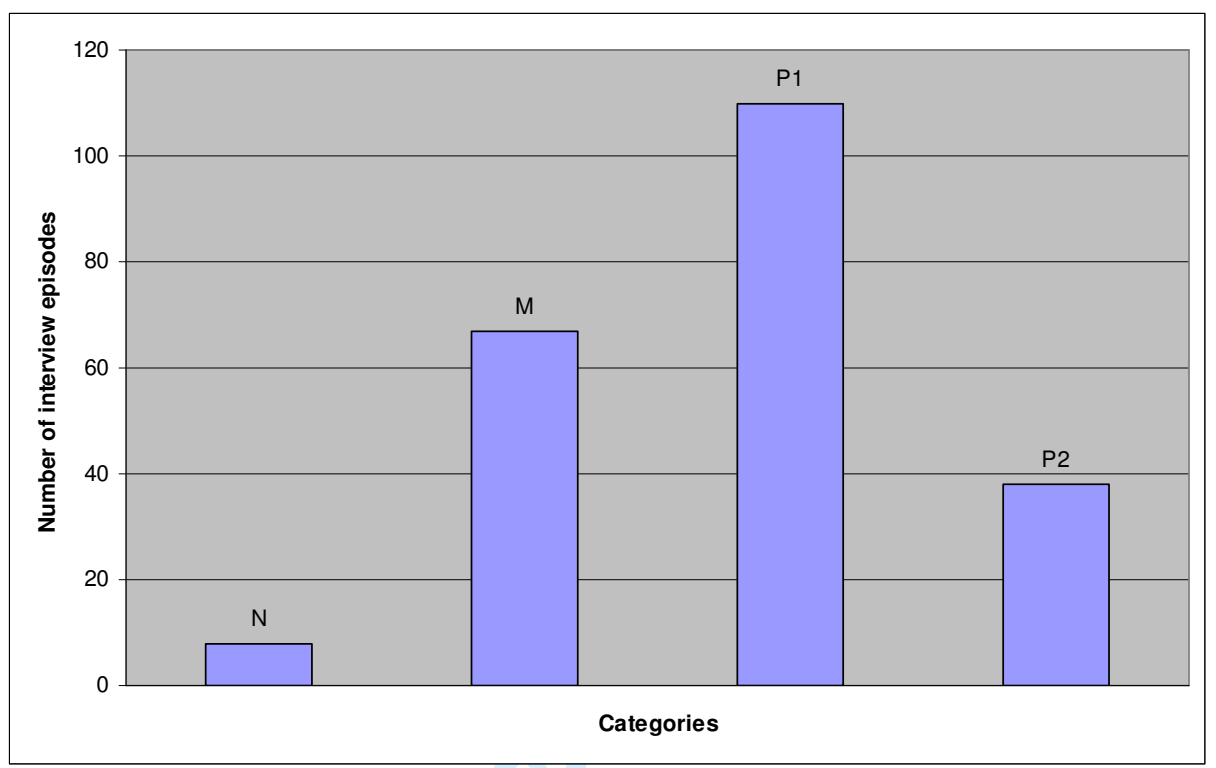

$\underline{\text { N: No explanation offered }}$

$\underline{\text { M: Explanations using macroscopic ideas only }}$

$\underline{\text { P1: Explanations using 'alternative' particle ideas }}$

P2: Explanations using particle ideas matching target knowledge 


\begin{tabular}{|c|c|c|c|c|c|}
\hline School & $\mathrm{Y} 7$ & $\mathrm{Y} 8$ & $\mathrm{Y} 9$ & $\mathrm{Y} 10$ & $\mathrm{Y} 11$ \\
\hline 1 & 3 & 4 & $3(2)$ & $4(3)$ & $3(2)$ \\
\hline 2 & - & - & 4 & 2 & - \\
\hline 3 & - & 4 & 6 & 4 & \\
\hline 4 & - & - & 1 & 2 & - \\
\hline 5 & - & - & 4 & 4 & - \\
\hline total & 3 & 8 & 18 & 16 & 3 \\
\hline
\end{tabular}

Table 1: The spread of interviews across schools and year groups (numbers in brackets show paired interviews) 


\begin{tabular}{|l|l|l|l|l|l|}
\hline Phenomenon & $\underline{\mathrm{N}}$ & $\underline{\mathrm{M}}$ & $\underline{\mathrm{P} 1}$ & $\underline{\mathrm{P} 2}$ & $\underline{*}$ \\
\hline $\begin{array}{l}\text { Dissolving potassium } \\
\text { permanganate }\end{array}$ & - & 6 & 8 & 3 & $\mathbf{1 7}$ \\
\hline Dissolving salt & 4 & 7 & 30 & 3 & $\mathbf{4 4}$ \\
\hline Recovering solute & 2 & 14 & 11 & 1 & $\mathbf{2 8}$ \\
\hline Evaporating water & - & 2 & 3 & 10 & $\mathbf{1 5}$ \\
\hline Stretching wire & - & - & 2 & 4 & $\mathbf{6}$ \\
\hline Compressing gas & - & - & - & 3 & $\mathbf{3}$ \\
\hline Floating ice & - & 3 & 7 & 2 & $\mathbf{1 2}$ \\
\hline Diffusing smell & 1 & 3 & 1 & 6 & $\mathbf{1 1}$ \\
\hline Miscible liquids & - & - & 9 & - & $\mathbf{9}$ \\
\hline Diffusing pigment & - & 10 & 10 & 2 & $\mathbf{2 2}$ \\
\hline Precipitation reaction & - & 2 & 15 & 2 & $\mathbf{1 9}$ \\
\hline Neutralization reaction & - & 1 & 3 & 1 & $\mathbf{5}$ \\
\hline Combustion reaction & - & 3 & 1 & - & $\mathbf{4}$ \\
\hline Insoluble solid & - & 5 & 5 & - & $\mathbf{1 1}$ \\
\hline Immiscible liquid & - & 11 & 4 & 1 & $\mathbf{1 6}$ \\
\hline Total & $\mathbf{8}$ & $\mathbf{6 7}$ & $\mathbf{1 1 0}$ & $\mathbf{3 8}$ & $\mathbf{2 2 3}$ \\
\hline
\end{tabular}

Table 2: Rating of episodes for the different phenomena discussed 


\begin{tabular}{|c|c|c|c|c|c|}
\hline year & $\begin{array}{c}\text { No of } \\
\text { episodes in } \\
\text { database }\end{array}$ & $\mathrm{N}$ & $\mathrm{M}$ & $\mathrm{P} 1$ & $\mathrm{P} 2$ \\
\hline $7(\mathrm{KS} 3)$ & 8 & 2 & 3 & 3 & - \\
\hline $8(\mathrm{KS} 3)$ & 16 & - & 6 & 9 & 1 \\
\hline $9(\mathrm{KS} 3)$ & 33 & 3 & 4 & 22 & 4 \\
\hline $10(\mathrm{KS} 4)$ & 28 & 1 & 14 & 12 & 1 \\
\hline $11(\mathrm{KS} 4)$ & 4 & - & - & 3 & 1 \\
\hline total & $\mathbf{8 9}$ & $\mathbf{6}$ & $\mathbf{2 7}$ & $\mathbf{4 9}$ & $\mathbf{7}$ \\
\hline
\end{tabular}

Table $\underline{3}$ : Classification of students' explanations of dissolving 


\begin{tabular}{|c|c|c|c|c|c|}
\hline year & $\begin{array}{c}\text { No of } \\
\text { episodes in } \\
\text { database }\end{array}$ & $\mathrm{N}$ & $\mathrm{M}$ & $\mathrm{P} 1$ & $\mathrm{P} 2$ \\
\hline $7(\mathrm{KS} 3)$ & 1 & - & - & 1 & - \\
\hline $8(\mathrm{KS} 3)$ & 2 & - & - & 2 & - \\
\hline $9(\mathrm{KS} 3)$ & 15 & 1 & 3 & 5 & 7 \\
\hline $10(\mathrm{KS} 4)$ & 19 & - & 5 & 4 & 9 \\
\hline $11(\mathrm{KS} 4)$ & 11 & $\mathbf{1}$ & $\mathbf{8}$ & $\mathbf{1 4}$ & $\mathbf{2 5}$ \\
\hline total & $\mathbf{4 8}$ & & & & 2 \\
\hline
\end{tabular}

Table 4: Classification of students' explanations of physical changes 


\begin{tabular}{|c|c|c|c|c|c|}
\hline year & $\begin{array}{c}\text { No of } \\
\text { episodes in } \\
\text { database }\end{array}$ & $\mathrm{N}$ & $\mathrm{M}$ & $\mathrm{P} 1$ & $\mathrm{P} 2$ \\
\hline $7(\mathrm{KS} 3)$ & 2 & - & 2 & - & - \\
\hline $8(\mathrm{KS} 3)$ & 2 & - & 1 & 1 & - \\
\hline $9(\mathrm{KS} 3)$ & 8 & - & 2 & 6 & - \\
\hline $10(\mathrm{KS} 4)$ & 16 & - & 5 & 10 & 1 \\
\hline $11(\mathrm{KS} 4)$ & 3 & - & - & 2 & 1 \\
\hline total & $\mathbf{3 1}$ & - & $\mathbf{1 0}$ & $\mathbf{1 9}$ & $\mathbf{2}$ \\
\hline
\end{tabular}

Table 5: Classification of students' explanations of mixing 


\begin{tabular}{|c|c|c|c|c|c|}
\hline year & $\begin{array}{c}\text { No of } \\
\text { episodes in } \\
\text { database }\end{array}$ & $\mathrm{N}$ & $\mathrm{M}$ & $\mathrm{P} 1$ & $\mathrm{P} 2$ \\
\hline $7(\mathrm{KS} 3)$ & 2 & - & 1 & 1 & - \\
\hline $8(\mathrm{KS} 3)$ & 6 & - & - & 5 & 1 \\
\hline $9(\mathrm{KS} 3)$ & 9 & - & - & 8 & 1 \\
\hline $10(\mathrm{KS} 4)$ & 8 & - & 2 & 5 & - \\
\hline $11(\mathrm{KS} 4)$ & 3 & - & 3 & - & $\mathbf{3}$ \\
\hline total & $\mathbf{2 8}$ & - & $\mathbf{6}$ & $\mathbf{1 9}$ & -1 \\
\hline
\end{tabular}

Table $\underline{6}$ : Classification of students' explanations of chemical reactions 


\begin{tabular}{|c|c|c|c|c|c|}
\hline year & $\begin{array}{c}\text { No of } \\
\text { episodes in } \\
\text { database }\end{array}$ & $\mathrm{N}$ & $\mathrm{M}$ & $\mathrm{P} 1$ & $\mathrm{P} 2$ \\
\hline $7(\mathrm{KS} 3)$ & 1 & - & 1 & - & - \\
\hline $8(\mathrm{KS} 3)$ & 2 & 1 & - & 2 & - \\
\hline $9(\mathrm{KS} 3)$ & 15 & - & 5 & 1 & - \\
\hline $10(\mathrm{KS} 4)$ & 6 & - & 1 & 1 & 1 \\
\hline $11(\mathrm{KS} 4)$ & 3 & $\mathbf{1}$ & $\mathbf{1 6}$ & $\mathbf{9}$ & $\mathbf{1}$ \\
\hline total & $\mathbf{2 7}$ & & & & 5 \\
\hline
\end{tabular}

Table 7: Classification of students' explanations of non-mixing 


\begin{tabular}{|l|c|c|c|c|c|}
\hline $\begin{array}{l}\text { Class of } \\
\text { Phenomena }\end{array}$ & $\begin{array}{c}\text { No of } \\
\text { episodes in } \\
\text { database }\end{array}$ & $\mathrm{N}$ & $\mathrm{M}$ & $\mathrm{P} 1$ & $\mathrm{P} 2$ \\
\hline Dissolving & 89 & 6 & 27 & 50 & 6 \\
\hline $\begin{array}{l}\text { Physical } \\
\text { changes }\end{array}$ & 48 & 1 & 8 & 14 & 25 \\
\hline Mixing & 31 & - & 10 & 19 & 2 \\
\hline $\begin{array}{l}\text { Chemical } \\
\text { reactions }\end{array}$ & 28 & - & 6 & 19 & 3 \\
\hline Immiscibility & 27 & $\mathbf{8 ( 4 \% )}$ & $\mathbf{6 7}(\mathbf{3 0 \%})$ & $\mathbf{1 1 0}(\mathbf{4 9 \%})$ & $\mathbf{3 8}(\mathbf{1 7 \%})$ \\
\hline Overall & $\mathbf{2 2 3}$ & 16 & 9 & 1 \\
\hline
\end{tabular}

Table $\underline{8}$ : The overall classification of interview episodes 


\begin{tabular}{|c|c|c|c|c|c|}
\hline year group & $\begin{array}{c}\text { No of } \\
\text { episodes in } \\
\text { database }\end{array}$ & $\mathrm{N}$ & $\mathrm{M}$ & $\mathrm{P} 1$ & $\mathrm{P} 2$ \\
\hline $7(\mathrm{KS} 3)$ & 14 & 2 & 7 & 5 & - \\
\hline $8(\mathrm{KS} 3)$ & 28 & - & 7 & 19 & 2 \\
\hline $9(\mathrm{KS} 3)$ & 80 & 4 & 18 & 46 & 12 \\
\hline $10(\mathrm{KS} 4)$ & 76 & 2 & 31 & 32 & 12 \\
\hline $11(\mathrm{KS} 4)$ & 21 & - & 4 & 8 & 12 \\
\hline total & $\mathbf{2 2 3}$ & $\mathbf{8}$ & $\mathbf{6 7}$ & $\mathbf{1 1 0}$ & $\mathbf{3 8}$ \\
\hline
\end{tabular}

Table 9: Classification of interview episodes by year group 
Notes:

\begin{abstract}
${ }^{\mathrm{i}}$ Although the UK is considered one nation with a national government, there are variations in the education systems in the different constituent countries. In particular, Scotland has a completely different curriculum to the rest of the UK. This paper refers to the English context, and the 'national' curriculum and 'national' tests here signify England.
\end{abstract}

I ii Under the ENC at the time of the study, students in state schools were expected to study mathematics, English and science through the 11 years of compulsory

schooling. The majority of upper secondary students followed a science course that is certified as equivalent to two subjects on leaving school ('double science'). There was the provision for students of low achievement (or those with strong linguistic skills who wish to study several foreign languages) to follow a more restricted science curriculum during the final two years of compulsory schooling ('single science').

Some students took biology, chemistry and physics as separate examinations subjects Deleted: are ('triple science'), where examination specifications also include additional topics not Deleted: take part of the mandated curriculum. 
Characterising the instructional context

In the Introductory sections to this paper we described the Curriculum context in England in terms of the extensive culture of 'guidance' offered to schools to inform classroom teaching. In terms of official intentions, teaching about particle ideas is a central focus of lower secondary science, featuring in yearly teaching objectives, and explicitly linked to many of the prescribed topics.

It is recognised that curriculum reform is a slow and complex process that can be impeded, frustrated or misdirected by a wide range of factors (e.g. Anderson, 1996). Whilst English schools are required to teach the prescribed curriculum, they have flexibility in responding to curriculum 'guidance' such as the Framework (DfES, 2002) and other outputs from the Strategy.

The five schools where our data were collected demonstrate this, so that the individual departmental schemes of work reflected, but did not necessarily directly adopt, the full model scheme issued by the curriculum authority (e.g. QCA, 2000). One of the five schools where we collected data reported that they did not explicitly use the Framework (DfES, 2002), or any other Strategy resources (despite schools being given funding resources to access the associated training). However, this school had adopted a commercial teaching scheme (called 'Framework Science') claimed by its publishers to be "perfectly in line with the approach and content of the Framework and QCA Scheme of Work" (http://www.oup.com/uk/catalogue/?view=oxed\&ci=9780199148967, accessed 14/01/2008). This suggests that some of the influence of the government initiatives may be indirect: whilst some individual schools may believe they have good reasons not to adopt government advice on pedagogy, market pressures nonetheless ensure that schemes available from commercial publishers are presented as fitting the current guidance.

The other schools involved in the study used commercial teaching schemes that could be considered to be modified versions of the recommended model. These schools engaged with the Strategy programme of teacher support for the recommended Framework (DfES, 2002). The (then) Head of Science in one of the schools described how departmental staff had undertaken "extensive training in all aspects of the KS3 Strategy" which was considered to have "had a big impact on the achievement of our pupils and improving standards".

The non-mandated nature of official 'guidance'; the tendency for most schools to wish to show they have been following what is set out as 'best practice'; and the indirect ways in which such officially sanctioned advice can influence practice make it difficult to establish a clear picture of the precise influence of the government initiatives on the learning of students. Observing the extent to which teaching actually adopted the recommended approaches was beyond the present study. It seems reasonable to assume 
that actual classroom practice in England reflects government 'guidance' to differing degrees, which seems to be the case in the schools involved in the present study.

Indications from the National Testing regime

Our findings from a modestly-sized convenience sample of learners, drawn unevenly from a small number of schools in one locality in England, would best be considered as 'suggestive'. We consider the possible implications of our own results below, but acknowledge that readers should bear in mind the limitations of our sample.

National surveys of student attainment in science were undertaken in the 1980s by the Assessment of Performance Unit (APU, 1989b) - a section of the government education ministry - providing National figures on student understanding of key areas of science (e.g. APU, 1989a) and providing useful information on student understanding about such areas as basic particle theory (Brook, Briggs \& Driver, 1984). However, the surveys were discontinued before the introduction of the National Curriculum and the subsequent increasing prescription of teaching approaches by successive UK governments, leaving gross outcomes on National Tests and school-leaving examinations as the main indicators available to government and others to monitor the effectiveness of curriculum policies and pedagogic advice

The National Testing regime reporting on student attainment at age 14 (at the end of the lower secondary 'key stage') is based around the assignment of students to 'levels' of attainment. Although the reported Test statistics only offer an overall view of student performance, reports produced for teachers offer some more specific indications of areas of weakness,

"The application of particle theory to pressure in liquids and gases is not well understood. ... pupils were unable to explain what happens to the spacing between particles when liquids and gases are put under pressure. In 1999, pupils had similar difficulties in explaining how air particles in a tyre exert a pressure"

QCA, 2001: 11

"[most pupils] could draw the arrangement of particles in a gas, but only a few recognised that when water vapour is condensed into water the gas molecules which are well separated come into loose contact with one another...pupils had to say what would happen to samples of copper sulphate solution left in an open and in a covered dish. Many pupils did not recognise that evaporation would be faster from the open dish because freely circulating air would allow the vapour particles to diffuse away easily."

QCA, 2003: 29-30

Such comments seem consistent with level descriptors (which refer to the full range of curriculum topics, not just particles) published in the curriculum documents, which suggest that the ability to apply particle ideas relates to attainment expected only at the higher levels. So at level 6 (which would be considered a high level of attainment at $\mathrm{KS} 3$ ), students will "recognise that matter is made up of particles, and describe 
differences between the arrangement and movement of particles in solids, liquids and gases". At level 7 they will typically,

"make links between the nature and behaviour of materials and the particles of which they are composed. They use the particle model of matter in explanations of phenomena. They explain differences between elements, compounds and mixtures in terms of their constituent particles"

\section{DfES/QCA, 1999}

Only at level 8 are students expected to be able to "use the particle model in a wide range of contexts". So-called 'exceptional performance' beyond level 8 is typified by students who "use particle theory in a wider range of contexts, recognising that differences in the properties of materials relate to the nature of the particles within them" and who understand how the particle model can be used in explaining physical phenomena such as how sweating causes cooling (DfES/QCA, 1999).

Students are assigned an overall level for their performance in the National Tests. According to government statistics (DfES, 2006), National Testing in 2006 showed that $26 \%$ of students were assigned Level 6 and 15\% attained level 7 (the highest level reported for this age group). The percentage of students attaining level 6 or above had not exceeded $40 \%$ in any of the previous 11 years of National Testing.

So by the end of KS3, about three-fifths of students are at level 5 or below. To the extent that levels assigned in National Tests can be considered to be reliably judged against the published level descriptors, it would seem that being able to apply the particle ideas taught to all is a characteristic expected of only a minority of students. This national picture lends some credence to our own findings (see Figure 3 and Table 7) as potentially relevant to the National context.

Familiarity without scientific understanding

In our study we found that a majority of students were familiar enough with the concept of particles, and were generally happy to talk about phenomena in these terms. It seems that in the contexts of the then extant version of the ENC it was not the case that most students failed "to invoke atoms and molecules as explanatory constructs" (Hesse \& Anderson, 1992: 277).

Yet there was limited appreciation of the way that scientists use particle models to explain the properties of materials in terms of the distinct conjectured properties assigned to the molecules, ions and so forth. So where students did call upon particle ideas, they commonly assigned particles the macroscopic properties to be explained, as has been noted in previous studies (e.g. Author1, 2001). So our study reflects the findings reported 
in the literature reviewed earlier (Nussbaum \& Novick, 1982; Ault et al, 1984; Ben-Zvi et al, 1986; Briggs \& Holding, 1986; Wightman et al, 1986; Renström et al, 1990; Griffiths $\&$ Preston, 1992; Author1, 2001), showing that even when students use particle ideas, they have considerable difficulty in doing so in scientifically accepted ways.

Our sample comprises students prepared to talk to us about their ideas from a number of secondary schools that we know to be strongly committed to teacher development and student achievement. So although our study does not form a representative survey of secondary students, we do consider o 